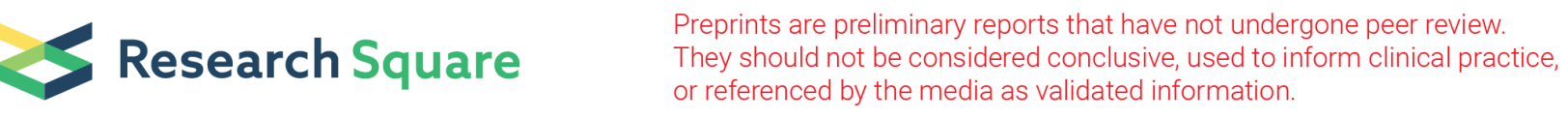

\title{
Strategies to Inform Innovations in Continence Care for People Living with Dementia in the Acute Hospital Setting: A Mixed Methods Narrative Synthesis Review
}

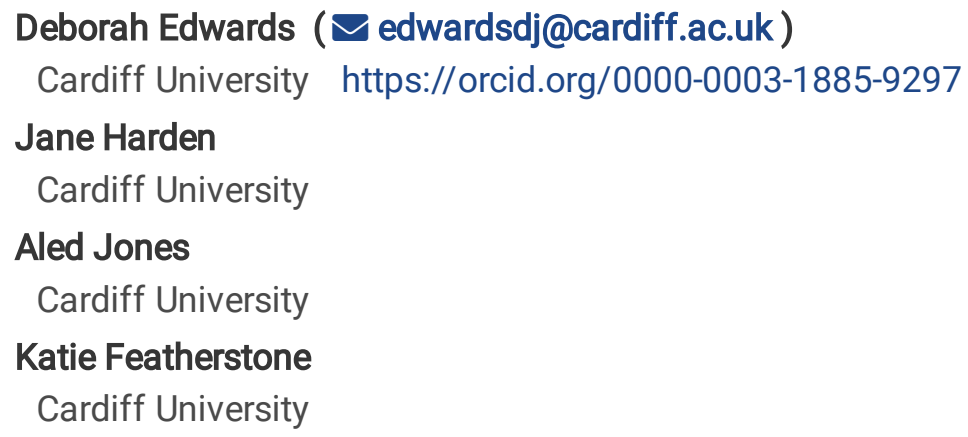

\section{Research}

Keywords: Dementia, continence, communication, individualised care, systematic review

Posted Date: September 21st, 2020

DOI: https://doi.org/10.21203/rs.3.rs-78042/v1

License: @ (i) This work is licensed under a Creative Commons Attribution 4.0 International License. Read Full License

Version of Record: A version of this preprint was published at Systematic Reviews on July 6th, 2021. See the published version at https://doi.org/10.1186/s13643-021-01743-0. 


\section{Abstract}

Background: People living with dementia are at significant risk of developing urinary and/or faecal incontinence but are also at risk of functional incontinence or being labelled as being incontinent. Despite the growing population of PLWD and importance of continence care little is known about the appropriate management, organisation, and interactional, strategies for PLWD admitted to acute hospitals. This mixed methods narrative systematic review sought to identify successful strategies across all care settings that could then be used to inform innovations in continence care for PLWD in the acute hospital setting.

Methods: In phase 1 a scoping search of two electronic databases (MEDLINE and PSYCinfo) and a consultation with stakeholders was undertaken. Findings from were presented to the project steering and two priority areas for phase 2 were identified which were communication and individualised care plans. In phase 2 eight databases and relevant UK government and other organisational websites were searched for English language citations from inception to August 2020. Critical appraisal was conducted using the Mixed Methods Appraisal Tool (MMA Version 11). Thematic synthesis was employed and the strength of synthesised findings for the intervention studies was assessed using the GRADE approach and the and confidence in synthesised qualitative and survey findings was assessed using the CERQual tool.

Results: In phase 1, 1348 citations were found and 75 included. In phase 2, 6247 citations were found 14 research studies and 14 policy and guidance documents were included. The quality of studies varied. Material was synthesized in order to identify the facilitators and barriers around developing communication strategies and individualised management plans in response to the continence needs of PLWD.

Conclusions: Recognising that PLWD are not always able to communicate their continence needs verbally is important. Incorporating interpersonal and communication skills into the context of continence care within training for those working with this patient group is crucial for continence to be maintained during an acute admission. Continence care in the acute setting should be tailored to the individual and be developed in partnership with staff and caregivers.

\section{Systematic review registration: PROSPERO: CRD42018119495}

\section{Background}

There are currently around 885,000 people living with dementia (PLWD) in the UK, [1] and around 50 million people worldwide [2]. This number is likely to increase to over two million in the UK [3] and 13.5 million worldwide by 2050 [4]. People living with dementia are at significant risk of developing urinary and/or faecal incontinence [5] and are at risk of functional incontinence or being labelled as incontinent. Urinary incontinence (UI) is described as "the complaint of any involuntary leakage of urine" [6, p. 1622] and is more common in older people. Faecal incontinence (FI) is defined as "the involuntary loss of liquid or solid stool that is a social or hygienic problem" [7, p. 199]. The prevalence of FI is higher in PLWD compared to others of similar age $[5,8]$. Functional incontinence on the other hand occurs when a usually continent person is unable to reach the toilet in time or as in PLWD an inability to recognise the need to go to toilet, locate the toilet or access the toilet [9], which is often a result of the environment they are in, rather than a feature of their dementia [10].

Dementia as a condition is often thought of as something initially cared for in the community, then later in specialist and long-term care settings, but the prominence of the acute hospital setting and its impact on PLWD cannot be ignored. The acute hospital setting has become a key site of care for PLWD. Internationally, prevalence estimates from a range of studies conducted since 2009 have reported that dementia was present in 18 to $42 \%$ of older adults admitted to hospital [11-15]. In the UK, the Department of Health in England acknowledges that at any given time, as many as one in four acute hospital beds will be occupied by a PLWD, who have been admitted with an additional acute condition [16, 17]. Although incontinence is recognised as a typical feature of advanced dementia, the majority of PLWD admitted to acute hospital wards with an unrelated condition are usually in the early and moderate stages of the disease, and thus, 
incontinence should not be a typical feature of their dementia [18]. Yet national acute audits conducted in the UK consistently identify PLWD and patients over 65 as being at high risk of being classified as incontinent and of receiving particularly poor continence care during acute admissions [19-21]. Studies have shown that a number of factors can contribute to the development of incontinence within hospital environments; including lack of appropriate signage, insufficient privacy, poor orientation, lack of toilets, and use of continence aids [22, 23]. As a result of such factors just over a third of LPWD who were hospitalised were reported to have developed UI at the time of discharge and, of those, $2 \%$ also developed FI for the first time [24].

Throughout the literature, nurses consistently report that 'containment' through the use of disposable pads and catheters is one of the key strategies for the management of continence for hospitalised older adults [25]. These approaches have implications for the occurrence of avoidable harm and patient outcomes during an acute admission; incontinence is a common risk factor for falls $[26,27]$ and catheters are associated with high rates of urinary tract infections [28]. These factors are also associated with a greater financial burden, prolonged hospitalisation, re-admission and increased mortality [29-31]. Incontinence can also be emotionally demeaning for patients [32] as well as being humiliating and embarrassing [33] and, combined with dementia, it increases the stigma [34] that PLWD already experience [35-37] which can have significant negative impacts on quality of life [38].

Despite the growing population of PLWD and importance of continence care for this group [39], little is known about the appropriate management, organisation and interactional strategies for PLWD admitted to acute hospitals [40]. Although several high quality reviews that have explored issues of continence for PLWD living at home [38, 41] and those living in longer-term care settings [8], only one previous review conducted just over 10 years ago examined incontinence care for PLWD across all care settings, focussing on assessment, management and prevention [40]. On conducting a scoping search of the literature, we identified very little empirical research examining continence care for PLWD in acute settings. It was therefore decided to conduct a mixed methods narrative systematic review across different care settings to identify successful strategies that could be used to inform innovations in continence care for PLWD in the acute hospital setting. This review was conducted as part of a wider ethnographic study that examined toileting, and continence strategies, within the overall context of ward care in the acute setting for PLWD [42].

\section{Methods}

\section{Design}

This systematic review used the two-stage Evidence for Policy and Practice Information and Co-ordinating Centre (EPPICentre) approach $[43,44]$. This involved a scoping of the overall area under review, followed by a targeted, in-depth, review and synthesis of the evidence in one or more sub-areas guided by key stakeholders in the field. We combined quantitative, qualitative, and non-research material (e.g. policies and guidelines) and these strands were brought together into an overall narrative synthesis [46]. The reporting of this systematic review has been developed in accordance with the recommendations from the Preferred Reporting Items for Systematic Reviews and Meta-Analyses (PRISMA) statement and PRISMA extension for scoping reviews $[45,46]$ The protocol has been registered in the International Prospective Register of Systematic Reviews (PROSPERO) (Registration: CRD42018119495).

\section{Scoping exercise}

The first stage was a scoping exercise which identified broad themes and patterns in the research area. Two databases were searched (MEDLINE and PsycINFO) from database inception to January 2018 for citations (a citation could be a research report, a review paper, a discussion piece, a published opinion, an editorial or something similar) that focused on, or contained an element relating to each of the following inclusion criteria:

1. PLWD, Alzheimer's disease (AD) or cognitive impairment

Page 3/39 
2. Acute, long-term and community healthcare and home settings

3. Urinary or faecal continence/incontinence, or toileting issues

4. Conservative management or care practices (defined as "any therapy that does not involve pharmacological or surgical intervention" [47, p. 1020] including catheterisation

Of the 1348 citations retrieved, 75 were included (see additional file S1 for PRISMA flow diagram). The findings were summarised into a number of broad, descriptive, maps [48] to identify the ways in which continence is assessed and managed across settings. The findings from the scoping exercise in keeping with the EPPI-Centre approach were presented to stakeholders with interest in the field in order to ascertain views on the priority areas for the second phase of searching. The key stakeholder groups included PLWD, family carers, and practitioners drawn from different occupational groups ( $\mathrm{n}=$ 32) and are shown in Table 1). All stakeholders as part of this process were asked to complete a priority setting exercise which was facilitated by answering the question. "What do you think are five of the most important ways that continence could be managed for PLWD when they are in hospital?" The responses from the individual and group consultations were collated, coded and grouped together and a list of the ways of managing continence in the hospital setting was generated. 
Table of stakeholders who took part in the consultation exercise

\section{Stakeholders Source of contact}

Source of information

\section{DCAs}

Young onset team DCA $(\mathrm{n}=1)$

REACT crisis team DCA $(n=1)$ (when a person has an additional mental health crisis on top of their dementia)

Community DCA's $(n=3)$

\section{SOLACE}

A service within the local University Health Board which exists to provide support to carers and those diagnosed with dementia, depression or severe later life mental illness. Their aim to help prevent admission to hospital and deterioration in relation to being in hospital.
Group discussion followed by priority setting exercise individual
DCA's

\section{Liaison Psychiatry}

A service that covers wards in the general hospital setting. Their role is to help PLWD when they are in hospital if there are struggling and who are exhibiting behaviours that challenge or if they are anxious or agitated such as walking around a lot and the staff aren't able to cope

\section{NHS Continence Service}

An outpatient based service. The role of the team is to accept and take referrals from primary care general practitioners (GP's), district nurses and others to see patients with incontinence and to assess and put in place a suitable management plan for them
Group interview followed by individual priority setting exercise

\section{Continence service team}

Nurse consultant $(\mathrm{n}=1)$

CNSs $(n=7)$

\section{Group discussion followed by individual priority setting exercise with CNSs}

Individual Interview with nurse consultant followed by setting exercise

\section{Occupational therapist ( $\mathrm{n}$ Facebook} $=1)$

Currently works on an elderly ward with both functional patients and PLWD. Previous employment was on a specific dementia ward in a community hospital

Individual interview followed by priority setting exercise

\section{Dementia Consultation Event}

A whole day event in which where issues around toileting and continence were explored through narrative and creative presentations (through pictures, poems and artistic expression, arts and discussion.

\section{Group} discussion followed by individual priority setting exercise

One activities coordinator of local care home $(n=1)$

Volunteer from the Alzheimer's society $(n=1)$

Key: CNS: clinical nurse specialists DCA: dementia care advisors; PLWD: people living with dementia

Descriptive maps of the findings from phase 1 and a summary of the consultation with the stakeholders were presented to the project steering group which included a family carer, the research and development director of nursing for a local health board and six researchers. Informed by the principles of nominal group technique [49,50], those present were invited to record on a "post it" note written responses to the question "What do you think are the most important ways that 
continence could be managed for PLWD when they are in hospital". After the meeting, items were coded and grouped together, and a list of ranked priority risk categories created and circulated to the project steering group for approval. Then the project steering group priorities were combined with the stakeholder priorities. The top two priority areas identified as having the most relevance to informing and improving continence care within the acute setting was 'communication' and 'individualised care planning', which were taken forward for the second in-depth phase of the review.

\section{Objectives}

For the second the specific objectives were to

1. To identify and explore carers', family members and health care professionals' (HCPs) perceptions and experiences of communication and the use of individualised management plans to support continence care for PLWD.

2. To identify and explore the communication strategies and individualised management plans that carers', family members and HCPs' use in response to the continence needs of PLWD.

3. To identify the facilitators and barriers around developing communication strategies and individualised management plans in response to the continence needs of PLWD.

\section{Eligibility criteria}

We used PICOS/PICo framework to guide the inclusion criteria on participants (P), intervention /phenomena of interest (I), comparators (C), outcome (O), study design (S) and context (Co)

\section{Participants}

PLWD or cognitive impairment and/or carers', family members and HCPs of PLWD or cognitive impairment. All dementia subtypes were included for example AD, vascular dementia, frontotemporal dementia etc.

\section{Interventions / Phenomena of interest}

Perceptions and experiences of individualised continence care or communicating about toileting and incontinence issues

Any communication strategy or individualised management plan/s

\section{Comparators}

All comparisons were considered

\section{Outcomes}

All outcomes as presented across the primary studies

\section{Study designs}

Quantitative (e.g. randomised controlled trials (RCTs), quasi experimental, cohort studies, descriptive studies), qualitative studies (e.g. focus groups or individual interviews), and non-research material (e.g. policies (UK only), guidelines, reports of practice initiatives and clinical case studies).

\section{Context}

All participants involved with the care of a PLWD in acute, long-term and community healthcare and home settings.

\section{Searching}

Searches were made for English language citations using the following eight databases, with time limits from database inception to June 2018 (updated August 2020). On the Ovid Platform: Medline: PsycINFO; EMBASE, on the EBSCO Platform: CINAHL, ERIC; on the ProQuest platform; ASSIA and Open Grey. Relevant UK government and organisational 
websites (for example Alzheimer's Society and Dementia UK) were searched. Keywords and index terms identified as relevant and reflecting the projects agreed priorities in phase 1 were used and individual search strategies developed for each database. This review also drew on the individual search strategies developed for the Cochrane Incontinence Review Group [51]. An example search strategy for Medline is provided in additional file S2.

To identify published resources that have not yet been catalogued in the electronic databases, recent editions of the Journal of Gerontological Nursing, American Journal of Alzheimer's Disease \& Other Dementia, Journal of the American Geriatrics Society and the Journal of Wound, Ostomy, \& Continence Nursing were hand-searched. Reference lists of included studies were scanned, experts contacted, and forward citation tracking performed using ISI Web of Science.

\section{Screening, quality appraisal and data extraction}

Screening and selection of all citations was conducted using standardised systematic review methods involving all members of the project team[52]. Multiple articles by the same authors reporting findings from the same study were linked together to help inform decisions on which studies to include. The methodological quality of all included research publications was independently assessed by two reviewers using Mixed Methods Appraisal Tool (MMAT-Version 2011). This tool was developed for the appraisal of methodological quality of qualitative, quantitative and mixed methods studies $[53,54]$. Any disagreement on quality was resolved through discussion with a third reviewer. Each study was assigned a score based on the number of criteria met (25\%-one criterion met; $100 \%$-all criteria met). Studies were excluded from the review if they scored less than $50 \%$ for quality, meaning that they fulfilled a maximum of only two of four criteria [53]. Nonresearch evidence (e.g. policies, reports) were not subjected to quality appraisal. Study findings for the primary research studies for the purposes of this review were considered to be all text that was labelled as results or findings. All nonresearch material were available as electronic documents and were searched using keywords relevant to the priority areas (for example communication, tailored, individual). This data were then considered to be findings and extracted and entered verbatim into Microsoft WORD (see additional file S3).

\section{Synthesis}

Thematic synthesis was employed to bring together data from both qualitative and quantitative primary research studies and non-research material [55]. The quantitative data was 'qualitised' whereby the extracted quantitative data was converted into textual descriptions to allow integration with the qualitative data. For all data descriptive codes and themes were generated through line by line coding of text of the findings and were developed inductively based on close reading of the content of all items included. The next step was to go beyond the content of the original studies to create analytical themes to see how the themes answered/addressed the study objectives [44]. To answer the third objective and to provide an overarching synthesis, the reviewers inferred what the barriers and facilitators were from the descriptive themes within the synthesized findings from the first two objectives.

The strength of the overarching synthesised findings for the intervention studies was assessed using the Grading of Recommendations Assessment, Development, and Evaluation (GRADE) approach [56]. This rates the quality of a body of evidence as high (further research is very unlikely to change our confidence in the estimate of effect), moderate (further research is likely to have an important impact on our confidence in the estimate of effect and may change the estimate), low (further research is very likely to have an important impact on our confidence in the estimate of effect and is likely to change the estimate) or very low (any estimate of effect is very uncertain). Confidence in over arching synthesised qualitative and survey findings was assessed using the Confidence in the Evidence from Reviews of Qualitative research (CERQual) tool [57]. The original CERQual approach was designed for qualitative findings but has previously been used by members of this research team in additionally adopting CERQual for the assessment of the confidence of synthesised findings from surveys and other non-intervention quantitative studies [58, 59]. The confidence of synthesised review findings is based on the assessment of four components: the methodological limitations of the qualitative studies contributing to a synthesised review finding, the relevance to the review question of the studies contributing to a 
synthesised review finding, the coherence of a synthesised review finding, and the adequacy of data supporting a synthesised review finding. Four levels are then used to describe the overall assessment of confidence as high, moderate, low or very low. When a synthesised review finding is assessed as being 'high confidence', this indicates that this synthesised review finding should be seen as a reasonable representation of the phenomenon of interest. If there are concerns with regard to any of the above four components, then this indication is weakened and a lower level of confidence attained [57].

\section{Results}

\section{Description of included material}

The database searches yielded a total of 6,247 citations after duplicates were removed (see Fig. 1). Fifteen research publications (consisting of 14 unique research studies) were included in the final review along with a total of 14 policy and guidance documents. Details of full text publications excluded from the review are provided in additional file S4.

\section{Characteristics of the included material}

Information on the characteristics of included research studies, including assessments of quality, are given in Tables 2 to 4 and details of the non-research material is available in additional file S4. 
Characteristics of included qualitative studies

\begin{tabular}{|c|c|c|c|}
\hline $\begin{array}{l}\text { Author/s, Year, Country } \\
\text { Aim }\end{array}$ & $\begin{array}{l}\text { Setting } \\
\text { Participants }\end{array}$ & $\begin{array}{l}\text { Demographic } \\
\text { details for PLWD }\end{array}$ & $\begin{array}{l}\text { Methods } \\
\text { MMAT score }\end{array}$ \\
\hline \multirow{6}{*}{$\begin{array}{l}\text { Study 1: Bliss et al., } 2013 \text { [70] } \\
\text { USA } \\
\text { To describe health literacy needs related } \\
\text { to incontinence and skin care among } \\
\text { family or friend caregivers of individuals } \\
\text { with AD and develop supportive and } \\
\text { educational materials that address these }\end{array}$} & Setting & Gender & Methods \\
\hline & Home & Female (75\%) & \multirow{5}{*}{$\begin{array}{l}\text { Focus groups } \\
\text { and Interviews } \\
\text { MMAT score: } \\
100 \%\end{array}$} \\
\hline & Participants & Age (Mean \pm SD) & \\
\hline & $\begin{array}{l}\text { Family/friend adult caregivers } \\
(\mathrm{n}=48)\end{array}$ & $64 \pm 14$ & \\
\hline & $\begin{array}{l}\text { Spouses (44\%), daughters } \\
\text { (31\%), or extended family } \\
\text { members/friends (25\%) }\end{array}$ & $\begin{array}{l}\text { Mental status } \\
\text { AD or Dementia }\end{array}$ & \\
\hline & $\begin{array}{l}\text { Recruited from community- } \\
\text { based agencies }\end{array}$ & & \\
\hline \multirow{2}{*}{$\begin{array}{l}\text { Study 1: Mullins et al., } 2016 \text { [71] } \\
\text { USA } \\
\text { To examine barriers to communicating } \\
\text { with healthcare professionals and health } \\
\text { literacy about incontinence among } \\
\text { different types of informal caregivers of } \\
\text { individuals with AD }\end{array}$} & Same as Bliss et al., 2013 & $\begin{array}{l}\text { see Bliss et al., } \\
2013\end{array}$ & \multirow{2}{*}{$\begin{array}{l}\text { see Bliss et al., } \\
2013 \\
\text { MMAT score: } \\
100 \%\end{array}$} \\
\hline & & & \\
\hline \multirow{7}{*}{$\begin{array}{l}\text { Study 2: Hutchinson et al., } 1996 \text { [87] } \\
\text { USA } \\
\text { To addresses the range and variation of } \\
\text { toileting problems, management } \\
\text { strategies used by family and employed } \\
\text { caregivers }\end{array}$} & Setting & \multirow{5}{*}{$\begin{array}{l}\text { Demographic } \\
\text { characteristics of } \\
\text { patients with } A D \\
\text { who attended the } \\
\text { day centre were } \\
\text { not reported }\end{array}$} & Methods \\
\hline & AD specific day Centre & & \multirow{3}{*}{$\begin{array}{l}\text { Participant } \\
\text { observation at } \\
\text { the day care } \\
\text { centre, clients' } \\
\text { home and } \\
\text { support groups }\end{array}$} \\
\hline & Home & & \\
\hline & Participants & & \\
\hline & $\begin{array}{l}\text { Family members who } \\
\text { participated in the centre } \\
\text { support groups }(n=16)\end{array}$ & & $\begin{array}{l}\text { Interviews with } \\
\text { families and } \\
\text { staff members }\end{array}$ \\
\hline & \multirow[t]{2}{*}{$\begin{array}{l}\text { Staff members employed at the } \\
\text { day care centre }(n=13)\end{array}$} & Mental status & $\begin{array}{l}\text { Based on } \\
\text { qualitative } \\
\text { ethology }\end{array}$ \\
\hline & & $A D$ & $\begin{array}{l}\text { MMAT score: } \\
75 \%\end{array}$ \\
\hline Study 3: Rolnick et al., 2013 [72] & Setting & Not applicable & Methods \\
\hline USA & Secondary care providers & Mental status & Interviews \\
\hline \multirow{3}{*}{$\begin{array}{l}\text { To examine healthcare providers' } \\
\text { perspectives regarding improving } \\
\text { communication with patients and their } \\
\text { caregivers about incontinence and } \\
\text { dementia }\end{array}$} & Participants & \multirow[t]{3}{*}{ Dementia } & \multirow{3}{*}{$\begin{array}{l}\text { MMAT score: } \\
100 \%\end{array}$} \\
\hline & $\begin{array}{l}\text { Physicians }(\mathrm{n}=8) / \text { Nurse } \\
\text { practitioners }(\mathrm{n}=2) / \\
\text { Pharmacist }(\mathrm{n}=1)\end{array}$ & & \\
\hline & $\begin{array}{l}\text { Potential participants suggested } \\
\text { by advisory committee }\end{array}$ & & \\
\hline
\end{tabular}

Key: AD: Alzheimer 's disease; MMAT: Mixed methods appraisal tool; PLWD: people living with dementia; SD: standard deviation 


\begin{tabular}{|c|c|c|c|}
\hline $\begin{array}{l}\text { Author/s, Year, Country } \\
\text { Aim }\end{array}$ & $\begin{array}{l}\text { Setting } \\
\text { Participants }\end{array}$ & $\begin{array}{l}\text { Demographic } \\
\text { details for PLWD }\end{array}$ & $\begin{array}{l}\text { Methods } \\
\text { MMAT score }\end{array}$ \\
\hline Study 4: Ostaszkiewicz et al., 2018 [73] & Setting & Not applicable & Methods \\
\hline Australia & Nursing Home & Mental status & Interviews \\
\hline \multirow{6}{*}{$\begin{array}{l}\text { To explore nursing home staff members' } \\
\text { beliefs and expectations about what } \\
\text { constitutes "quality continence care" for } \\
\text { people living in nursing homes }\end{array}$} & Participants & \multirow{6}{*}{$\begin{array}{l}\text { Most nursing } \\
\text { home residents } \\
\text { were cognitively } \\
\text { impaired }\end{array}$} & \multirow{4}{*}{$\begin{array}{l}\text { Naturalistic } \\
\text { inquiry using a } \\
\text { qualitative } \\
\text { exploratory } \\
\text { descriptive } \\
\text { research } \\
\text { approach }\end{array}$} \\
\hline & Nursing home staff $(n=19)$ & & \\
\hline & Registered nurses $(n=8)$ & & \\
\hline & Enrolled nurses $(n=4)$ & & \\
\hline & Personal care workers $(n=7)$ & & \multirow{2}{*}{$\begin{array}{l}\text { MMAT score: } \\
100 \%\end{array}$} \\
\hline & $\begin{array}{l}\text { Recruited using snowballing } \\
\text { technique; selective placement } \\
\text { of information in print and } \\
\text { electronic media; and } \\
\text { information sessions at several } \\
\text { nursing homes }\end{array}$ & & \\
\hline Study 14: Scerri et al 2018 [74] & Setting & Gender & Methods \\
\hline Malta & Acute medical wards $(n=3)$ & Age (Mean) years & Interviews \\
\hline \multirow{5}{*}{$\begin{array}{l}\text { To categorise the perceived and observed } \\
\text { needs of persons with dementia admitted } \\
\text { in acute medical wards and to explore } \\
\text { whether these needs are being or have } \\
\text { been met. }\end{array}$} & Participants & 84.7 & \multirow{4}{*}{$\begin{array}{l}\text { Observations } \\
\text { using } \\
\text { Dementia Care } \\
\text { Mapping }\end{array}$} \\
\hline & \multirow{4}{*}{$\begin{array}{l}\text { PLWD and their family members } \\
(n=12)\end{array}$} & & \\
\hline & & Mental status & \\
\hline & & Dementia & \\
\hline & & & $\begin{array}{l}\text { MMAT score: } \\
75 \%\end{array}$ \\
\hline $\begin{array}{l}\text { Key: AD: Alzheimer 's disease; MMAT: Mixe } \\
\text { deviation }\end{array}$ & methods appraisal tool; PLWD: $p$ & le living with dem & a; SD: standard \\
\hline
\end{tabular}


Table 3

Characteristics of included descriptive studies

\begin{tabular}{|c|c|c|c|}
\hline $\begin{array}{l}\text { Author/s, Year, Country } \\
\text { Aim }\end{array}$ & $\begin{array}{l}\text { Setting } \\
\text { Participants }\end{array}$ & $\begin{array}{l}\text { Demographic } \\
\text { details for } \\
\text { PLWD }\end{array}$ & $\begin{array}{l}\text { Data collection } \\
\text { Outcome measures } \\
\text { MMAT score }\end{array}$ \\
\hline \multicolumn{4}{|l|}{ Cross sectional surveys } \\
\hline \multirow{13}{*}{$\begin{array}{l}\text { Study 7: Wilkinson et al., } \\
1995 \text { [67] } \\
\text { Australia } \\
\text { To evaluate the comparative } \\
\text { suitability of a range of } \\
\text { words or symbols to label a } \\
\text { toilet for people with } \\
\text { dementia }\end{array}$} & Setting & Gender & Data collection \\
\hline & \multirow[t]{3}{*}{$\begin{array}{l}\text { Phase 1: Hostel care for } \\
\text { ambulant people with } \\
\text { dementia }(n=24 / 28, \operatorname{rr} 86 \%)\end{array}$} & $\begin{array}{l}\text { No details } \\
\text { provided } \\
\text { Age (years) }\end{array}$ & $\begin{array}{l}\text { Phase 1: questions posed to } \\
\text { hostel management on what } \\
\text { word and/or symbols were } \\
\text { already in use in that institution } \\
\text { to label toilet and/or bathroom } \\
\text { facilities }\end{array}$ \\
\hline & & & $\begin{array}{l}\text { Phase 2: questions asking } \\
\text { preference for toilet door labelling }\end{array}$ \\
\hline & & & Outcome measures \\
\hline & \multirow{4}{*}{$\begin{array}{l}\text { Phase 2: Aged care complex } \\
\text { with hostel and nursing home }\end{array}$} & \multirow[b]{2}{*}{$\begin{array}{l}80.4(95 \% \mathrm{Cl} \\
77.1-83.1)\end{array}$} & $\begin{array}{l}\text { Preferred symbol according to } \\
\text { cognitive state }\end{array}$ \\
\hline & & & $\begin{array}{l}\text { Preferred word according to } \\
\text { cognitive state }\end{array}$ \\
\hline & & Mental status & \multirow[t]{7}{*}{ MMAT score: $100 \%$} \\
\hline & & Folstein MSE & \\
\hline & $\begin{array}{l}\text { facilities }(n=28) \text { and an acute } \\
\text { hospital ward }(n=20)\end{array}$ & $\begin{array}{l}\text { Normal } \\
\text { cognition }(n= \\
21)\end{array}$ & \\
\hline & Participants & $\begin{array}{l}\text { Mild dementia } \\
(\mathrm{n}=11)\end{array}$ & \\
\hline & $\begin{array}{l}\text { Phase } 1: n=24 \text { institutions } \\
\text { Phase } 2: n=24 \text { patients }\end{array}$ & $\begin{array}{l}\text { Moderate } \\
\text { dementia }(n= \\
\text { 16) }\end{array}$ & \\
\hline & & $\begin{array}{l}\text { Severe } \\
\text { dementia } \\
\text { excluded }\end{array}$ & \\
\hline & & $\begin{array}{l}\text { The study } \\
\text { comprised two } \\
\text { phases and } \\
\text { questionnaires } \\
\text { were used in } \\
\text { both }\end{array}$ & \\
\hline
\end{tabular}

Key: AD: Alzheimer 's disease; Cl: confidence intervals; MMAT: Mixed methods appraisal tool; MSE: mental state examination PLWD: people living with dementia; SD: standard deviation 


\begin{tabular}{|c|c|c|c|}
\hline $\begin{array}{l}\text { Author/s, Year, Country } \\
\text { Aim }\end{array}$ & $\begin{array}{l}\text { Setting } \\
\text { Participants }\end{array}$ & $\begin{array}{l}\text { Demographic } \\
\text { details for } \\
\text { PLWD }\end{array}$ & $\begin{array}{l}\text { Data collection } \\
\text { Outcome measures } \\
\text { MMAT score }\end{array}$ \\
\hline $\begin{array}{l}\text { Study 12: Shih et al., } 2015 \\
\text { [68] } \\
\text { Taiwan } \\
\text { To understand and compare } \\
\text { the behavioural } \\
\text { characteristics of bowel } \\
\text { movement and urination } \\
\text { needs in patients with } \\
\text { dementia }\end{array}$ & $\begin{array}{l}\text { Setting } \\
\text { Long term care facilities }(n=8) \\
\text { Day centre }(n=1) \\
\text { Participants } \\
\text { Residents }(n=187)\end{array}$ & $\begin{array}{l}\text { Gender: } \\
\text { Female (59\%) } \\
\text { Age (mean } \pm \\
\text { SD) years } \\
80.1 \pm 9.6 / \\
\text { Range } 70 \text { to } \\
90 \\
\text { Mental status } \\
\text { AD 38.5\% } \\
\text { Unspecified } \\
\text { dementia } \\
32.6 \% \\
\text { Vascular } \\
\text { dementia } \\
18.7 \% \\
\text { Other } \\
\text { dementia } \\
10.2 \%\end{array}$ & $\begin{array}{l}\text { Data collection } \\
\text { Behaviour checklist for bowel and } \\
\text { urination developed for the study } \\
\text { Outcomes measures } \\
\text { Symptom's and signs of bowel } \\
\text { movement and urination } \\
\text { expressed by the patient }\end{array}$ \\
\hline
\end{tabular}

An adapted three-stage Delphi consultation study

Key: AD: Alzheimer 's disease; Cl: confidence intervals; MMAT: Mixed methods appraisal tool; MSE: mental state examination PLWD: people living with dementia; SD: standard deviation 


\begin{tabular}{|c|c|c|c|}
\hline $\begin{array}{l}\text { Author/s, Year, Country } \\
\text { Aim }\end{array}$ & $\begin{array}{l}\text { Setting } \\
\text { Participants }\end{array}$ & $\begin{array}{l}\text { Demographic } \\
\text { details for } \\
\text { PLWD }\end{array}$ & $\begin{array}{l}\text { Data collection } \\
\text { Outcome measures } \\
\text { MMAT score }\end{array}$ \\
\hline $\begin{array}{l}\text { Study 13: lliffe et al., } 2015 \\
\text { [69] } \\
\text { UK } \\
\text { Phase } 4 \\
\text { The aim of this study was to } \\
\text { develop and test a } \\
\text { continence assessment tool } \\
\text { and supporting resources for } \\
\text { people with dementia, to be } \\
\text { used by primary care } \\
\text { professionals, primarily } \\
\text { community nurses (pg 95) }\end{array}$ & 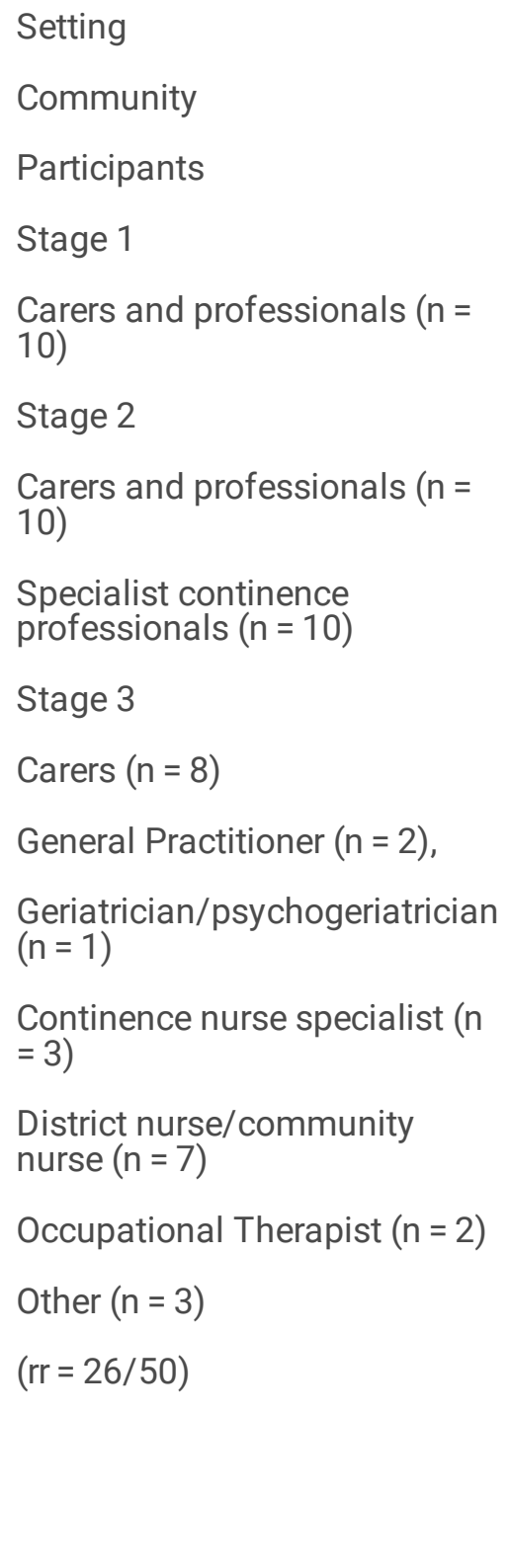 & $\begin{array}{l}\text { Not applicable } \\
\text { Mental Status } \\
\text { Dementia }\end{array}$ & $\begin{array}{l}\text { Data Collection } \\
\text { Stage 1: Face to face } \\
\text { consultations were facilitated to } \\
\text { describe a broad range of } \\
\text { principles and issues that would } \\
\text { underpin an assessment tool } \\
\text { designed to address the needs of } \\
\text { people with dementia } \\
\text { Stage 2: A prototype dementia- } \\
\text { focused continence assessment } \\
\text { tool was developed using the } \\
\text { data generated in stage 1, asking } \\
\text { for agreement or disagreement to } \\
\text { items plus suggestions for further } \\
\text { items. This was used to consult, } \\
\text { in writing, both the expert group in } \\
\text { stage } 1 \text { and also a further group } \\
\text { of carers and specialist } \\
\text { continence professionals. The } \\
\text { prototype was further adapted. } \\
\text { Stage } 3 \text { : A different, wider group } \\
\text { of experts (carers and } \\
\text { professionals) was consulted in } \\
\text { writing. They were sent the draft } \\
\text { dementia-focused assessment } \\
\text { tool together with a questionnaire } \\
\text { to test its face and content } \\
\text { validity. } \\
\text { Outcome measures } \\
\text { Recipients were asked (1) } \\
\text { whether or not the tool would } \\
\text { improve recognition of the } \\
\text { problems (face validity) and (b) } \\
\text { to rate each item for importance } \\
\text { and identify missing or } \\
\text { unnecessary items (content } \\
\text { validity) } \\
\text { MMAT score: } 75 \%\end{array}$ \\
\hline
\end{tabular}

Key: AD: Alzheimer 's disease; Cl: confidence intervals; MMAT: Mixed methods appraisal tool; MSE: mental state examination PLWD: people living with dementia; SD: standard deviation 
Table 4

Characteristics of included quantitative experimental studies

\begin{tabular}{|c|c|c|c|}
\hline Author/s, Year & Setting & Intervention & Data collection \\
\hline Country & Participants & & Outcome measures \\
\hline Aim & $\begin{array}{l}\text { Demographic } \\
\text { details for } \\
\text { PLWD }\end{array}$ & & MMAT score \\
\hline
\end{tabular}

\section{Case series with non-concurrent multiple baseline design}

Study 5: Lancioni et al., Setting Intervention

2009 [61]

USA

The present three pilot studies assessed the effectiveness of verbal instructions, presented automatically through simple technology, in helping persons with mild-to-moderate $A D$ recapture basic daily activities instructions

Alzheimer
rehabilitation
centre
Participants
Residents with
AD $(\mathrm{n}=3)$
Gender: Female
$(100 \%)$

Age (years): 79, 81,86

Mental status

$A D$

MMSE scores: $10,19,22$

\section{Intervention}

Baseline: Pilot study 1: The participants were to perform the bathroom routine without the help of the technology and related verbal

\section{Intervention: Pilot} study 1: The participants performed all bathroom-routine steps with the help of the technology, which presented the instructions Step 1 was "sit on the toilet". 17 steps in total and step 1 was "to sit on the toilet"

Study 6: Lancioni et al., 2009 [60]

\section{USA}

To assess the effectiveness of verbal instructions (presented automatically through simple technology) in helping persons with mild or moderate $A D$ perform daily living activities
Intervention

Same as Lancioni et al 2009a

Four studies with the first one aimed at replicating pilot study 1 from Lancioni et al 2009a. efforts directed at reestablishing the performance of morning bathroom routine

\section{Setting}

Alzheimer rehabilitation centre

Participants

Residents with $A D(n=4)$

Gender: Female (100\%)

Age (years): 59 , $76,79,85$

Mental status

AD

MMSE scores:

$11,12,16,20$

\section{Data collection}

The participants' performance of a step was recorded as 'correct' if it matched the description of such step (and the instruction available for it during the intervention) and occurred independent of prompting by research assistants

Outcome measures

Percentage of correct steps performed

MMAT score: $100 \%$

Data collection

Same as Lancioni et al 2009a

Outcome measures

Same as Lancioni et al 2009a

MMAT score: $100 \%$

\section{Randomised control trials}

Key: AD: Alzheimer's Disease; Cl: confidence intervals: C: control; I: intervention; IST: individualized scheduled toileting; MMAT: mixed methods evaluation tool; MSE: mental state examination, OT: occupational therapist; PLWD: people living with dementia; RCT: randomised controlled trial, RR: response rate; SPMSQ: Short Portable Mental Status Questionnaire; Ul: urinary incontinence 


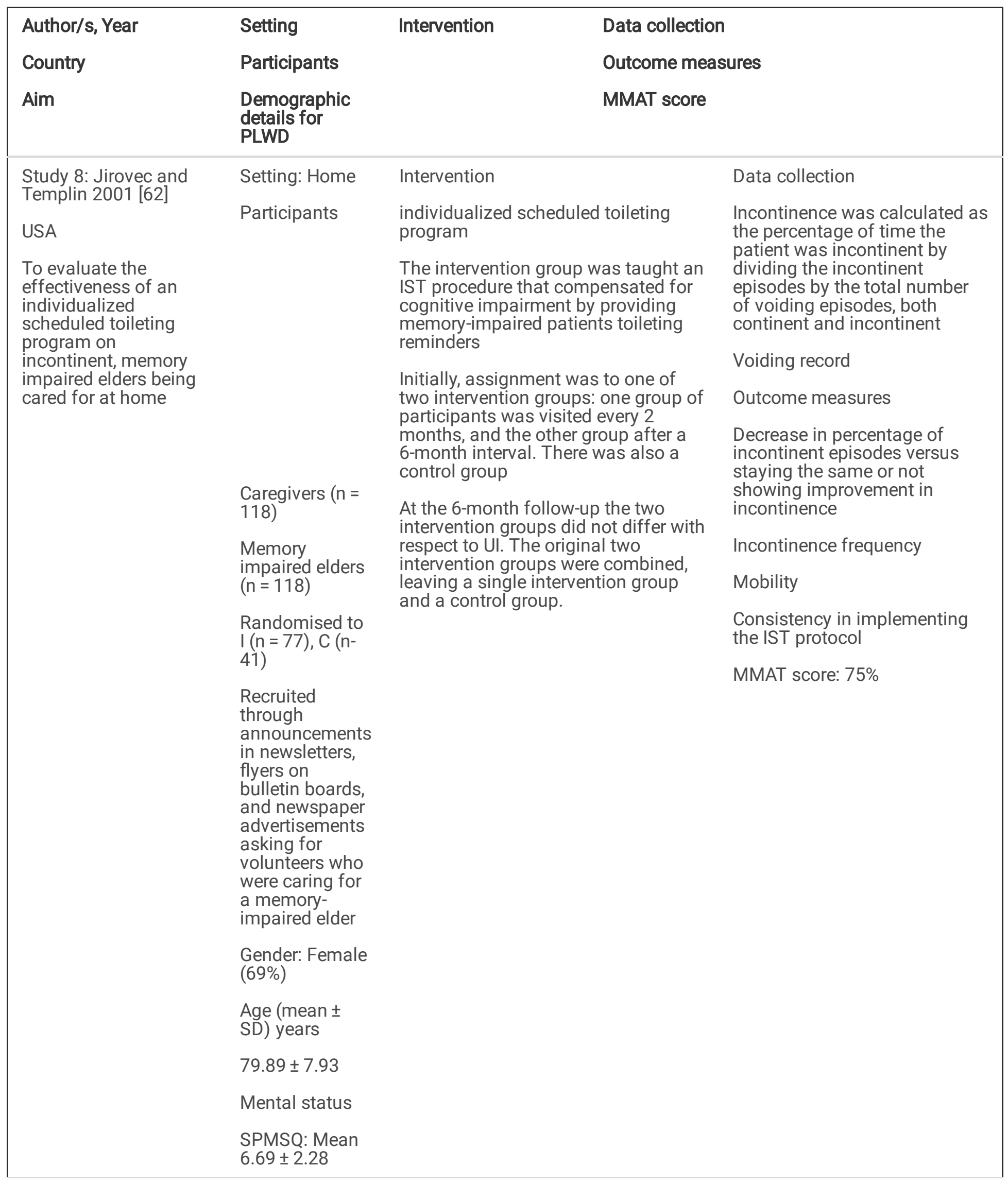

Key: AD: Alzheimer's Disease; Cl: confidence intervals: C: control; I: intervention; IST: individualized scheduled toileting; MMAT: mixed methods evaluation tool; MSE: mental state examination, OT: occupational therapist; PLWD: people living with dementia; RCT: randomised controlled trial, RR: response rate; SPMSQ: Short Portable Mental Status Questionnaire; Ul: urinary incontinence 


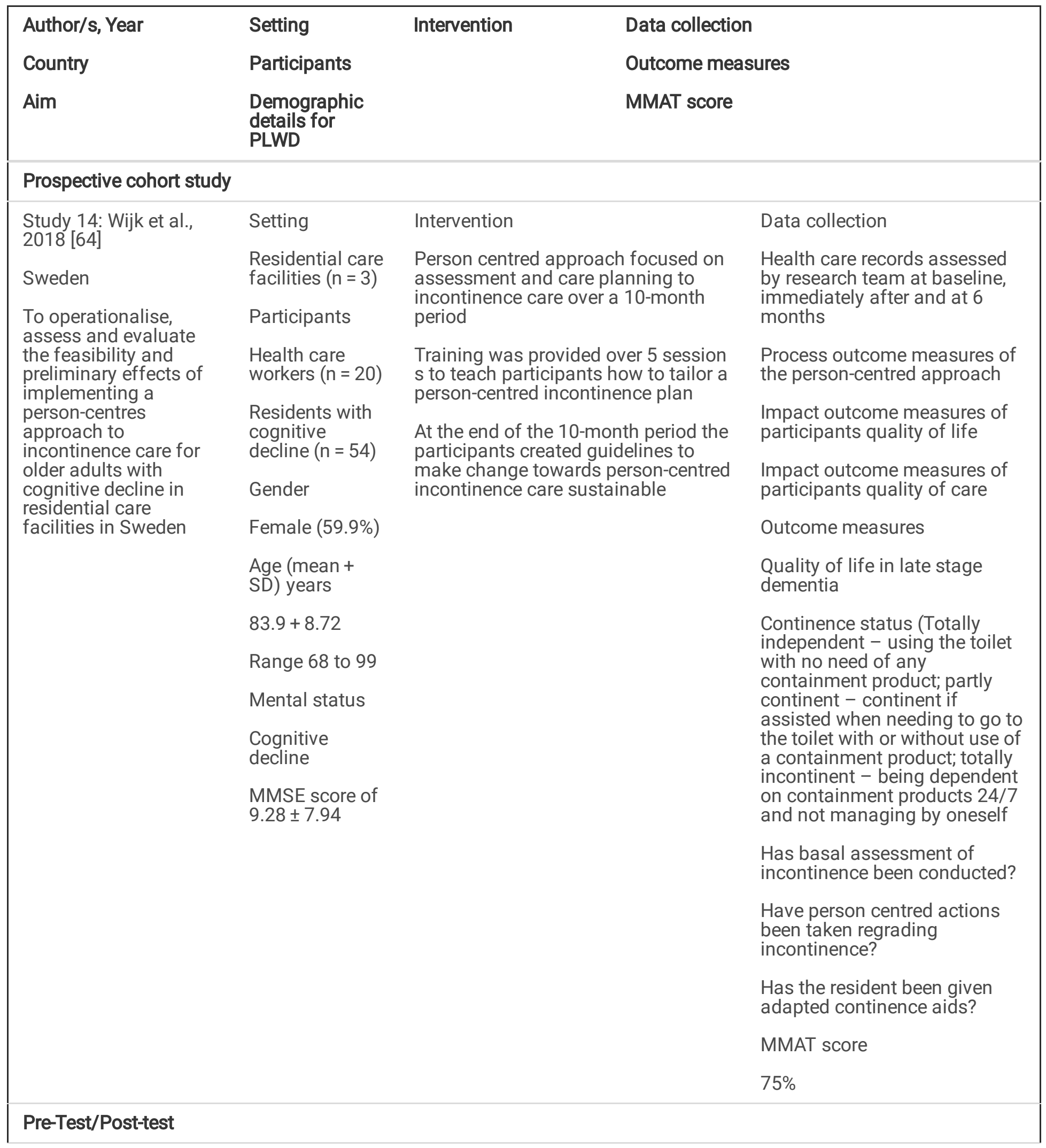

Key: AD: Alzheimer's Disease; Cl: confidence intervals: C: control; I: intervention; IST: individualized scheduled toileting; MMAT: mixed methods evaluation tool; MSE: mental state examination, OT: occupational therapist; PLWD: people living with dementia; RCT: randomised controlled trial, RR: response rate; SPMSQ: Short Portable Mental Status Questionnaire; Ul: urinary incontinence 


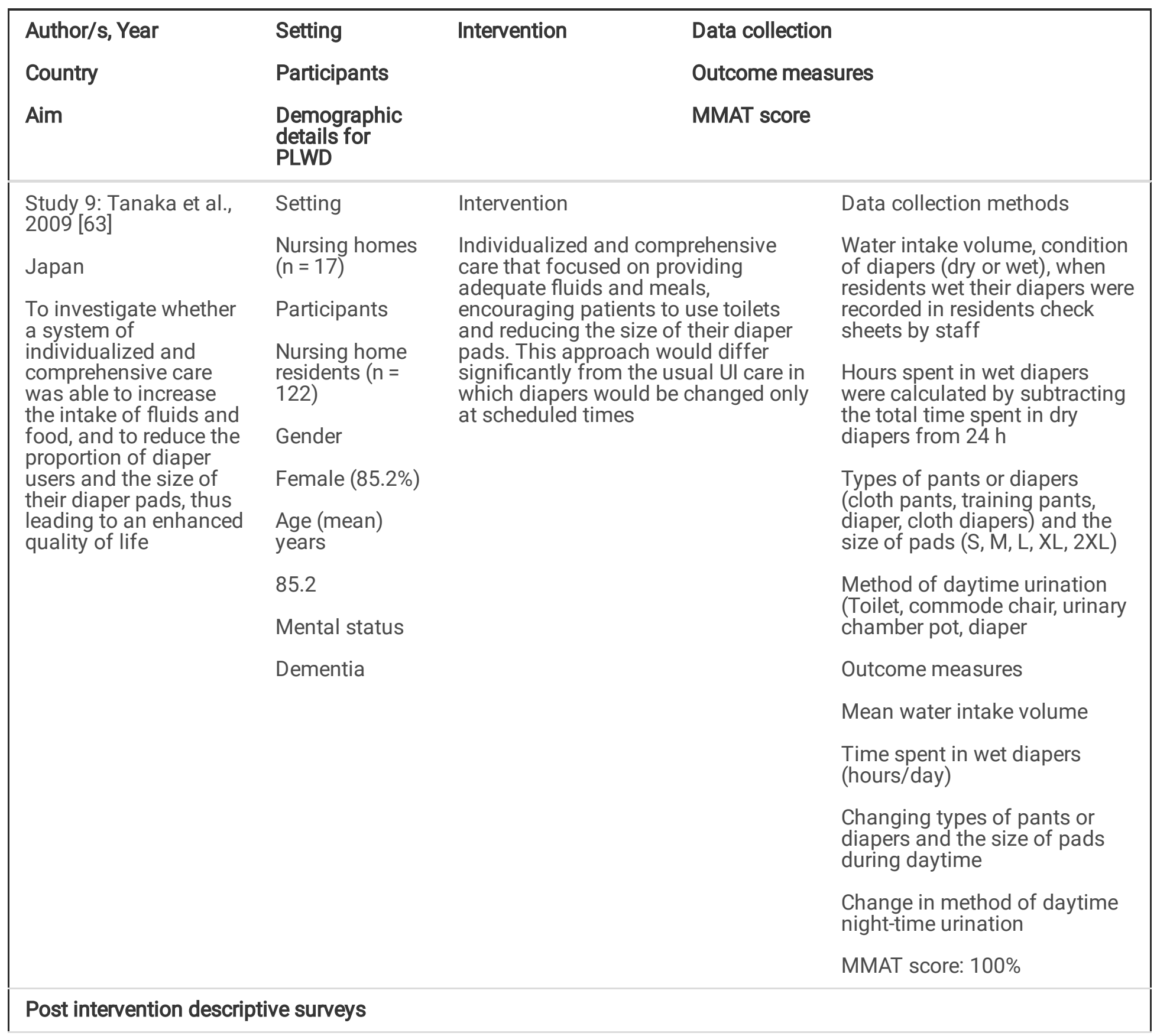

Key: AD: Alzheimer's Disease; Cl: confidence intervals: C: control; I: intervention; IST: individualized scheduled toileting; MMAT: mixed methods evaluation tool; MSE: mental state examination, OT: occupational therapist; PLWD: people living with dementia; RCT: randomised controlled trial, RR: response rate; SPMSQ: Short Portable Mental Status Questionnaire; Ul: urinary incontinence 


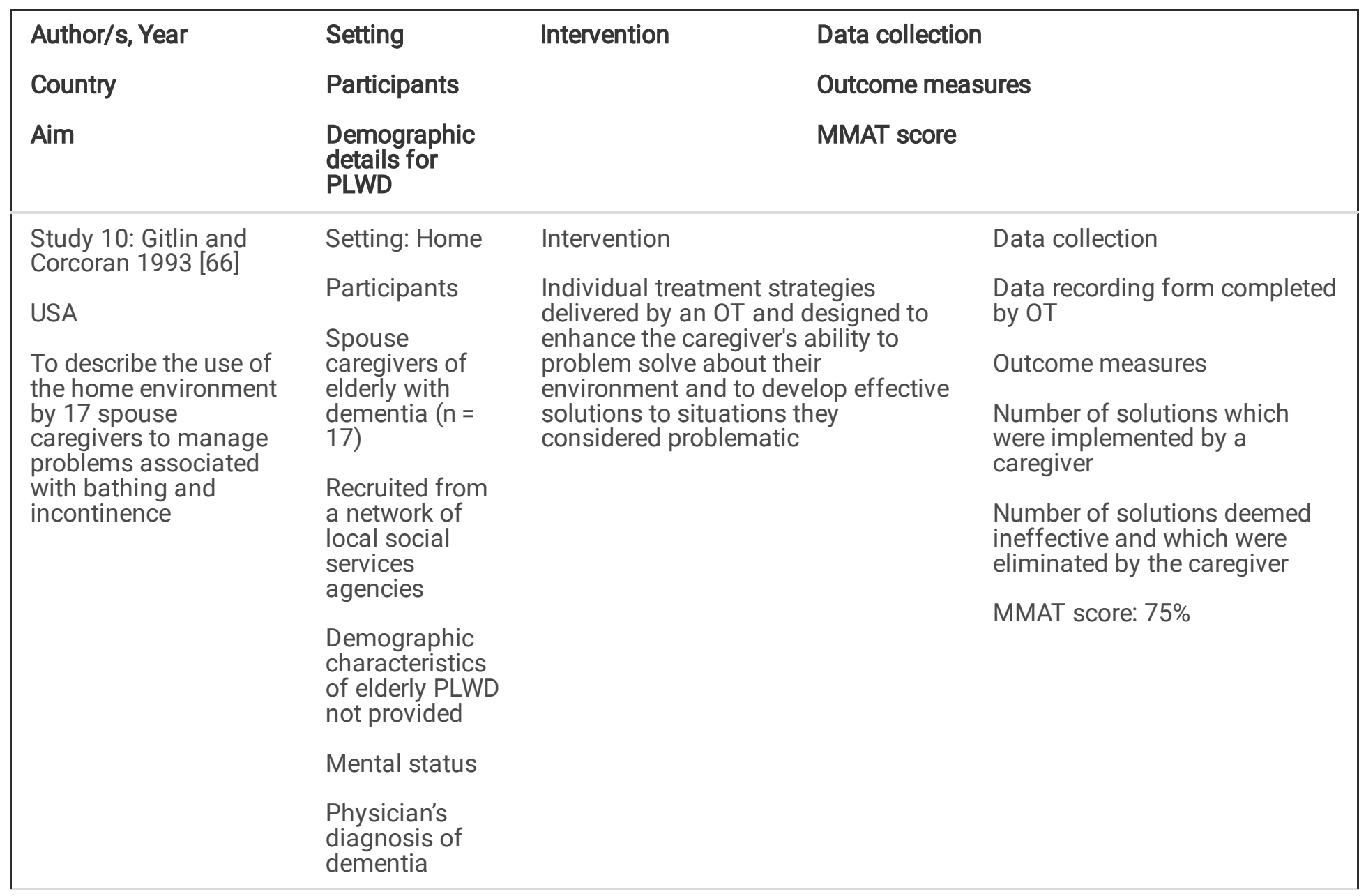

Key: AD: Alzheimer's Disease; Cl: confidence intervals: C: control; I: intervention; IST: individualized scheduled toileting; MMAT: mixed methods evaluation tool; MSE: mental state examination, OT: occupational therapist; PLWD: people living with dementia; RCT: randomised controlled trial, RR: response rate; SPMSQ: Short Portable Mental Status Questionnaire; Ul: urinary incontinence 


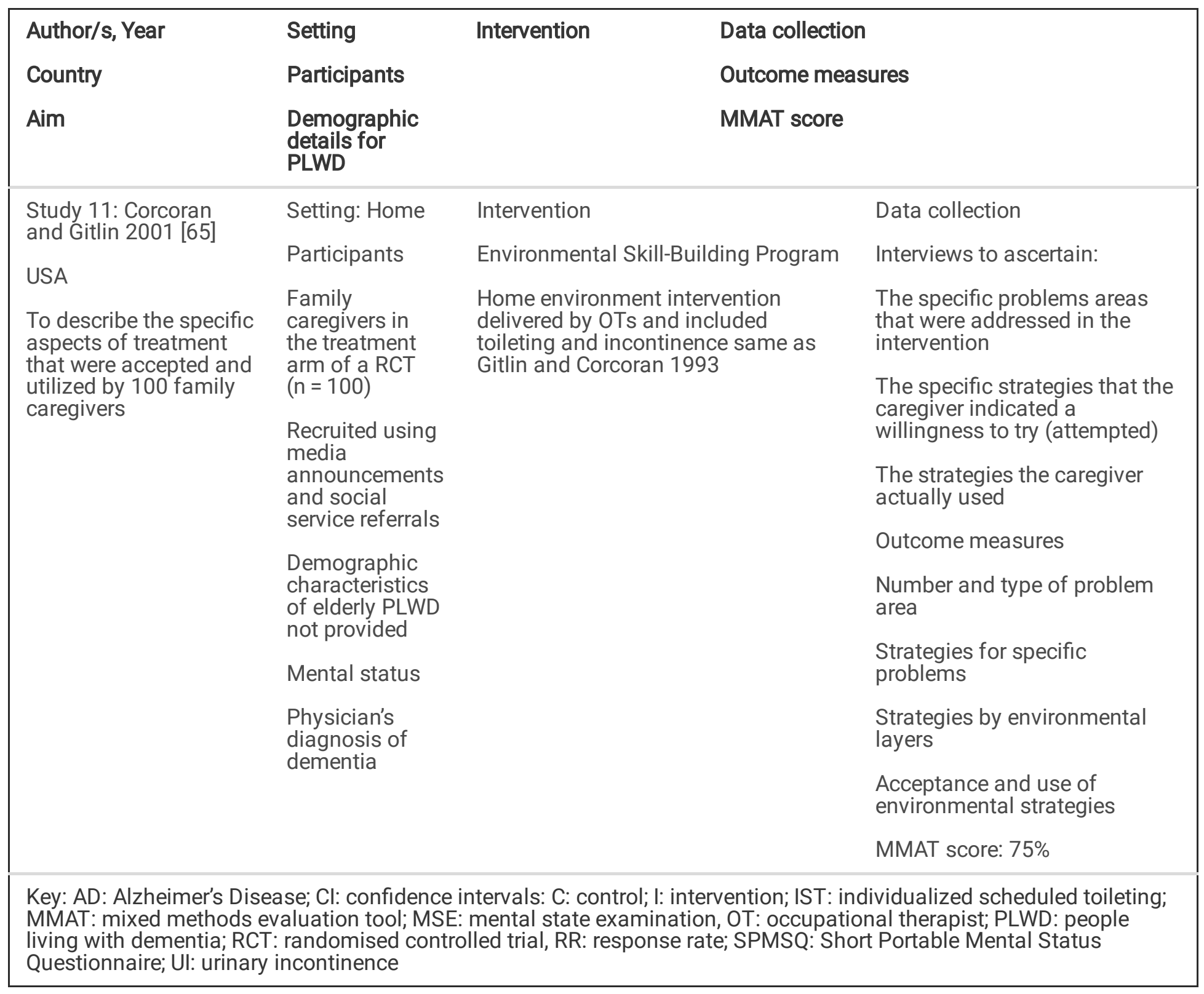

The research studies used a variety of research methodologies which included case series with non-concurrent multiple baselines $(n=2)$ [60, 61], RCT [62], pre-test/post-test [63], prospective cohort study [64], post intervention descriptive surveys $(n=2)[65,66]$; cross sectional survey $(n=2)[67,68]$, an adapted three-stage Delphi consultation study [69] and qualitative methods ( $n=4$, across 5 publications) [70-74]. The non-research material consisted of web pages/web booklets $(n=5)$ [75-79], guidelines $(n=2)[10,80]$, reports $(n=2)$ [81, 82], guidelines/guidance $(n=2)[33,83]$, framework $(n=1)$ [84], model $(n=1)$ [85] and information sheets $(n=1)$ [86]. Seven research studies were conducted in the USA [60, $61,65,66,70,72,87]$, two in Australia [67, 73] and one in each of the following countries; UK [69], Japan [63], Taiwan [68], Malta [74] and Sweden [64]. Only four of the non-research materials were published outside of the UK with one European guideline [10], one international guideline [33] and the framework and the model published by the same author from Australia $[84,85]$. The research studies were conducted across a variety of settings which included the home care and community setting $(n=5)[62,65,66,69,70]$, nursing homes $(n=2)[63,73]$, AD rehabilitation centres $(n=2)[60,61]$, secondary care settings $(n=3)[68,72,74]$, residential treatment facility [64] and across multiple locations (AD specific day centre and home care setting [87] or hostel care for ambulant people with dementia, aged care complex with hostel and nursing home facilities and an acute hospital ward [67] or day centre and long term care facility (LTCF) [68]). Across studies participants included PLWD $[67,74]$, residents of nursing homes who had a diagnosis of $\operatorname{AD}[60,61]$, residents of 
LTCFs with cognitive decline[68], family members or caregivers of PLWD [62, 65, 66, 69, 70, 74, 87], day centre staff [87], care centre managers [67] nursing home staff [73], primary care providers [69] and secondary care providers [69]. Rolnick et al., conducted their study with a number of secondary care providers and these were physicians, nurse practitioners and pharmacists [72].

\section{Quality assessment of included research studies}

The overall quality across the studies was variable. Two of the four qualitative studies fulfilled all four quality criteria on the MMAT, with the remaining two studies fulfilling three of the quality criteria, but did not report whether the researcher's role might influence the outcome of the study [74,87]. The RCT fulfilled three out of the four quality criteria, with the complete outcome data ( $80 \%$ or above) not reported [62]. There were six quantitative non-randomised studies and of these three fulfilled all four quality criteria $[60,61,63]$, for two studies it was not possible to ascertain the response rate for the sample $[65,66]$ and the other did not compare the base line characteristics between those in the control and intervention groups [64]. The remaining three studies were quantitative descriptive, two studies fulfilled all four criteria $[67,68]$ and the study that did not, we were unable to ascertain what the response rate was for the sample [69].

\section{Narrative synthesis}

The first objective was to identify and explore carers', family members and HCP's perceptions and experiences of communication and the use of individualised management plans to support continence care for PLWD. Eight themes were identified: communicating in a dignified way, attitudes of HCPs towards continence and continence care, presence of PLWD during outpatient consultations, initiating conversations during outpatient consultations, the language of incontinence during outpatient consultations, the importance of non-verbal cues, finding the appropriate words and symbols to describe the toilet and the importance of individualised continence care. Some aspects of these themes inevitably overlap as they are all in some way related to communication.

\section{Communicating in a dignified way}

The importance of protecting personal and social dignity $[72,73,87]$ during continence care was significant and HCPs reported a belief that PLWD and their caregivers prefer not to talk about incontinence because it is a highly embarrassing $[72,73]$ and distressing issue [85]. Health care professionals believed that the provision of quality continence care for PLWD includes measures and approaches that conceal incontinence by creating situations that allowed PLWD to go to the toilet in private and avoiding communication which revealed their issues around incontinence or care dependence that could cause them to feel embarrassed, ashamed or humiliated [73].

The importance of respecting PLWDs right to privacy was also considered important $[73,85,87]$. In order to relieve PLWD perceived embarrassment of accepting assistance [73, 87], HCPs stressed the importance of building rapport and trust, using humour [85] and "acting natural " [87, p. 24] when supporting continence needs. Health care professionals also felt that in order to communicate with PLWD in ways that would minimise any emotional impact that HCPs should have the appropriate knowledge and skills [73]. Other strategies to enhance privacy included whispering to the client about toileting issues [73] and keeping these issues secret [87]. However, HCPs acknowledged that PLWD may have difficulties in recognising and communicating their continence needs and that not being verbally being able to request toileting assistance was viewed a barrier to protecting dignity [73]. Closely overlapping with this theme of communication is the issue of HCPs attitudes towards continence care.

\section{The attitudes of HCPs towards continence and continence care}

The language used within a care environment is important regarding continence care [81, 84] and is not always respectful [81] but where staff had good knowledge of the people they cared for, then they were respectful and built good

Page 20/39 
relationships with PLWD [81]. Ostaszkiewicz et al., [84] on discussing coercive continence care practices, described them as including the use of verbal or physical force to wash a person, to accept wearing incontinence pads or other forms of incontinence containment and to accept continence checks" [84 p. 2]. The authors also suggest that chastising a person for being incontinent could be said to be a form of verbal abuse. Although some ward staff promote continence, this does not appear to happen consistently within acute settings [74]. Relatives expressed concern that PLWD would be happy to go to the toilet if assistance was provided, but that staff encouraged them to "do it in the nappy" [74 p. 8]. Other times, it was found that in some cases, routine toileting was avoided, and cues ignored when staff members were busy, or appeared uncomfortable with or disinterested in providing support [74, 87]. Ostaszkiewicz [84] recognised that "Communicating therapeutically about incontinence with any person, including people with dementia, involves the demonstration of warmth, compassion and humanity" [84 p. 523]. This is a skill that requires both clinical knowledge and interpersonal and communication skills, which should all be included within education programs [85]. Both formal caregivers and family carers would benefit from such programs, which would also enable the development of "empathetic understanding" [84 p. 8] to the emotions that a PLWD has in response to incontinence and its care [84].

\section{Presence of PLWD during outpatient consultations}

There is a lack of consensus as to whether PLWD should be present with their caregivers during outpatient consultations [70-72]. Health care providers believed that care recipients should be present when discussing continence problems during consultations [72], however, caregivers expressed mixed opinions [70,71]. Caregivers who favour this approach, view the $\mathrm{HCP}$ as an authority in this subject, with the result that they believe the PLWD would be more likely to cooperate with management strategies because they had been involved in the discussion [70]. Whereas those who opposed this reported that they did not want to upset or make their care recipient anxious by discussing a problem that the PLWD might not fully understand or be able to control [70]. Those caregivers who were daughters, felt the need to be sensitive to their parent's privacy and feelings, preferring to discuss incontinence in greater depth with their HCPs this finding was not found for spouses. However, time constraints or inability to meet alone with the HCPs prevented in-depth discussions from taking place [71]. Some caregivers suggested that HCPs could explain the problem and management options in simple terms when the care recipient was present in outpatients and then speak separately to the caregiver, providing more details [70].

\section{Initiating conversations during outpatient consultations}

There was a lack of consensus with regard to whom caregivers' thought should be responsible for initiating conversations about incontinence during dementia related consultations within outpatient settings [70-72]. Caregivers believed that it is the responsibility of HCPs to initiate conversations about incontinence during both initial consultations and follow up appointments [70]. However, there were differences depending on whether the care recipient was a parent or a spouse. Caregivers who were daughters or daughters in law would only discuss incontinence with HCPs when it became problematic to manage at home, whereas husbands tended to communicate their wives' problems much sooner [71]. In contrast HCPs thought that conversation about incontinence should be initiated by the caregiver [70]. However, when HCPs did initiate conversations about incontinence, they reported that this was appreciated by the caregiver who was receptive and engaging in discussion around the topic [72]. However, within secondary care, not all HCPs saw addressing incontinence as a priority and thought that the topic should be dealt with by the patient's primary care providers rather during a specialist secondary care referral [72]. Extended family and friends who were caregivers reported that HCPs don't always ask about incontinence during consultations [71]. A lack of awareness of available resources or concerns about frightening patients/caregivers about potential problems before they occurred, was suggested as possible explanations as to why HCPs do not routinely discuss incontinence and fail to initiate conversations about incontinence [72]. Time was found to be the most common barrier reported by HCPs to discussing incontinence, because they believed that a lot of information needed to be covered during the appointments and discussing incontinence issues can take more time than was typically allocated [72]. Possible solutions suggested by HCPs were for the patient/caregiver to have a follow up appointment to discuss incontinence or to offer referrals to a nurse in continence care [72].

Page 21/39 


\section{The language of incontinence during outpatient consultations}

Caregivers desired "straight talk" from HCPs about incontinence and its management in relation to PLWD [70]. Hispanic caregivers stressed that it was essential for providers to discuss incontinence using language that those with English as a second language can understand. They strongly supported having written materials about incontinence in PLWD and treatment plans available in Spanish [71]. During outpatient consultations caregivers rarely used the term incontinence, instead use terms such as having accidents, leaking, losing control, wetting or messing their pants, having a urine/bowel problem, urgency, diarrhoea, loose bowels, being unable to hold it, and not getting there in time, difficulty in getting to the bathroom, leaking, soiling themselves [70,72]. Health care providers also tend to adopt these terms when discussing incontinence with family caregivers or patients [72]. Caregivers when questioned said that they did not know the right terms and didn't want to be disrespectful to their care recipients. However, once they were made aware of the term incontinence, they were happy to use it [70].

\section{The importance of non-verbal cues}

People living with dementia are not always able to recognise and communicate that they need to go to the toilet or indicate that they need assistance $[10,60,61,65-67,70,72,73,78,79,81,87]$. It is therefore important to recognised the nonverbal signals, body language, facial expressions, behaviours and any signs that the PLWD uses to communicate in such instances $[78,79,81,87]$ so that their wishes can be acknowledged [81]. Listening carefully to the words or phrases that PLWD use for describing the toilet $[67,77,79-81]$ as well as being able to recognise familiar gestures $[67,80,81]$ is seen as important. New staff should be trained to recognize the importance of toileting and to how to understand individual behaviours and non-verbal cues in relation to toileting [87].

A range of different non-verbal cues had been observed or reported and include:

- someone pulling/taking off their clothing when they need to go to the toilet $[10,68,78]$

- making particular sounds such as moaning or grunting $[68,78,87]$

- assuming a different posture [37]

- someone looking around [87]

- fidgeting $[10,77,86,87]$

- getting up and walking around or pacing $[76,77,86,87]$ or restlessness $[10,68]$

- holding their crotch or their stomach $[10,77,87]$

- different facial expressions such as worry [10] or sorrow [68]

- going to the corner of the room [77]

- pulling at their clothes $[10,86]$

Hutchinson et al., [87] also reported a number of affective cues which included anger, profanity and acting frustrated and irritable. One study investigated common behaviours when PLWD experience either bowel movement or urination needs, found that anxiety, restlessness, and taking off/putting on clothes inappropriately occurred in more than $30 \%$ of patients [68].

\section{Finding the appropriate words and symbols to describe the toilet}

Wilkinson et al., [67] sought to evaluate the comparative suitability of a range of words or symbols to label a toilet for PLWD. As part of an institutional survey $(n=24)$ the words that were used to label the toilet were "toilet " $(67 \%)$,

"Male/Female" (11\%) and there in some institutions there was no labelling (22\%). Only four institutions used symbols, and these included the international symbol $(n=1)$, toilet symbol $(n=1)$, yellow wrapping over door $(n=1)$ and ceramic plaque upon which was written the word "Toilet". A further survey was conducted with participants living with dementia and was 
reported within the same publication and the preferred word and symbol for toilet varied significantly $(p<0.05)$ according to their level of dementia (which had been assessed using the Folstein mental state examination and classified as normal, mild, moderate and advanced). "Ladies" or "Gents" was preferred by those with normal cognition and "toilet" by those with moderate dementia. The international symbol (male and female symbols) was preferred by people with normal cognition or mild dementia whilst the toilet symbol was preferred by those with more advanced dementia [67].

\section{The importance of individualised continence care}

Targeted and individualised/person centred continence care $[10,33,73,75,79,82]$ that is established after a thorough clinical assessment has taken place $[10,33,84,86]$ is seen as being important. This would include the use of a bladder diary [10]. Individualised care continence care is described as about what is best for the PLWD [10, 79], avoiding harm [10] and about promoting autonomy and independent living [10].

\section{Objective two}

The second objective was to identify and explore the communication strategies and individualised management plans that carers', family members and HCPs use in response to the continence needs of PLWD. Six themes were created: general communication strategies, communication strategies for outpatient appointments, using technology to present instructions, components of individualised care plans, HCPs and caregivers working in partnership and establishing a toilet routine within the home environment.

\section{General communication strategies}

A number of general communication strategies between HCPs and PLWD have been suggested.

- To reduce anxiety/fear / embarrassment it is important to check HCPs awareness of good communication techniques when working with PLWD [69]

- Prompting $[10,78,80,81]$

- Get to know the PLWD [78] and how they communicate [79]

- Health care providers introducing themselves and seeking PLWD approval before performing tasks [73]

- Ask the PLWD how you can help them manage their continence [77]

- Communicate with the family to determine usual behaviour patterns [87]

- Get to know the PLWD such as previous routines, habits and lifestyle [77, 79]

- Don't make assumptions and see the person as an individual [79]

Caregivers reported that they sought additional information about incontinence from the internet but were concerned about the accuracy of the information retrieved, whether they could understand it, and had concerns about their searching skills [71]. They wanted support and reassurance that they were providing the care that was required and they wanted information before any problems such as incontinence occurred so that they could feel prepared [70].

One further study described how nursing staff communicated with residents' families about methods to manage incontinence when taking the PLWD "on an outing'[73 p. 2432] The advice included information about how to check and change pads, how to assist the resident to the toilet, and how long pads could potentially last without needing to be changed [73].

\section{Communication strategies for outpatient appointments}

There were a number of recommendations presented by both caregivers and HCPs in terms of resources that could be provided for the caregivers attending outpatient consultations [70-72] for example: 
- A guide for caregivers was developed that covered talking to a health care provider about these problems; with definitions of common clinical terms [70]

- A pre-visit check list or written materials of some type so that patients/caregivers could indicate whether incontinence was present, this could then prompt the HCP to start a discussion during the consultation [72]

- Readily available handouts that would offer more detailed explanations of what had been covered during the appointment [72]

- Short, focused handouts that could stand alone and address a single concern [72]

\section{Using technology to present instructions}

Two pilot studies $[60,61]$ conducted by the same authors explored the effectiveness of verbal instructions, presented automatically through simple technology, in helping persons with mild-to-moderate AD regain basic daily activities. The technology consisted of a modified Walkman with recordings of verbal instructions that directed the PLWD to undertake bathroom related activities in a certain order. Sensors detected when a PLWD entered the bathroom prompting the first instruction telling them to sit on the toilet. After a long pre-determined interval this instruction was then followed by another instruction for them to wash their hands with the soap. The Walkman was activated by a battery-powered, radiofrequency photocell, light-reflecting paper, and a microprocessor-based electronic control unit. Data from both studies showed that the use of verbal instructions and basic technology to control their presentation has the potential to be effective in helping people with mild or moderate AD recapture relevant daily activities, including toileting $[60,61]$.

\section{Components of individualised care plans}

A number of different components that may be considered as part of individualised care plans have been identified which include; being theory based [33], being concerned with the practical issues [75], and involved multi-components exploring both day time and night care of incontinence [33]. There was a general consensus that the needs of both PLWD and their caregivers need to be considered [10,33,82-84]. The advice given by the Alzheimer's Society was that a continence care plan should be tailored to the individual. This should aim "to cure toilet problems or incontinence wherever possible" [75 webpage]. Other components to consider include changing medication [75], changes to lifestyle [75], exercise [75], skin care [33, 84], manipulating the type, quantity and timing of food and drink [75], describe support available from HCPs [75] and follow up advice [75].

Ostaszkiewicz et al., [84] comments that nurses and care workers need support in order to develop individualised strategies to "optimize the care-dependent person's rest/sleep in the context of the person's concurrent need for continence and skin care" [84 p524/5]. Three studies described individualised care plans as part of wider interventions $[63,65,66]$. One was conducted within nursing homes and one member of staff from each home was selected to take part in a training program who then became responsible for educating other staff members. The intervention in this instance was multi-faceted covering individualised and comprehensive care that focused on providing adequate fluids and meals, encouraging patients to use toilets and reducing the size of their incontinence pads. This approach differed significantly from the usual Ul care in which incontinence pads would be changed only at scheduled times. Improvements across the different methods of urination were observed (incontinence pads, commode, urinary chamber pot) with only $11 \%$ of residents showing improvements during the day which were non-significant, whereas $19 \%$ of residents showed significant improvement during the night, changing from using incontinence pads to using the toilet. Overall a large number of residents' toileting remained unchanged following the intervention [63].

Two studies $[65,66]$ evaluated an environmental skill-building program which was a home environment individualised intervention delivered by occupational therapists, which included toileting and incontinence. The intervention was designed to enhance the caregiver's ability to problem solve about their environment and to develop effective solutions to situations they considered problematic. The study by Gitlin and Corcoran [66] was a pilot study and the 59\% of caregivers reported incontinence as problematic in their daily management routine. Problems included night-time and/or daytime incontinence 
of the bladder and/or bowel, resistance to toileting, or confusion as to how to perform an aspect of the toileting task. Seventeen effective caregiver initiated environmental solutions for incontinence were observed and of these, nine solutions (53\%) were accepted by the caregivers and integrated into their management routine by visit five of the intervention. For the later study by Corcoran and Gitlin [65] 29\% of caregivers identified continence as a problem area that needed addressing. Twenty-six attempted strategies that involved assistive devices and of these, 21 (81\%) were used. Fifty-one attempted strategies to manipulate the type, quantity and timing of food and drink and 46 (90\%) were used. The authors did not provide any further detail on the nature of the assistive devices.

One further study implemented a person-centred approach that focused on incontinence for residents with cognitive decline in residential treatment facilities [64]. The health workers were provided with training, however only 20 out of 100 participated although the process outcomes were measured among all residents who agreed to participate in the study. There were no statistically significant mean differences in quality of life scores before and after the intervention or between control and intervention participants. However, the quality of care improved for the intervention participants in that, fewer aids were needed to manage incontinence and an increased number of UI assessments were conducted.

\section{Health care professionals and caregivers working in partnership}

The importance of HCPs and caregivers working together to deliver individualised/person centred continence care was a feature of three intervention studies $[62,65,66]$ and was encouraged within four pieces of non-research material $[75,79$, $82,83]$. Within one intervention study nurse practitioners worked with the carer to plan the schedule for the PLWD and this was followed up with monthly phone calls and bi-monthly visits [62]. Occupational therapists worked with the caregivers in a further two intervention studies $[65,66]$ to deliver solutions to toileting and incontinence problems, which consisted of five visits over two [65] or three months [66]. Other HCPs that work with PLWD and their caregivers include continence advisors [75] or other HCPs specialising in continence care [79]. Working in partnership with caregivers and PLWD is important $[75,79,83]$ and enables HCPs to gather their personal story [82] to work out the best solutions and to ensure that specialist help can be accessed when needed and so that what is recommended is achievable [75].

\section{Establishing a toileting routine within the home environment}

The importance of developing a regular toileting schedule was discussed briefly within one study [66] and one piece of non-research material [10] and was the focus of one intervention study [62]. The intervention group in the study by Jirovec and Templin [62] were taught an individualised scheduled toileting procedure, which compensated for cognitive impairment by providing memory impaired patients with toileting reminders such as verbal prompts. Initially, assignment was to one of two intervention groups: one group of participants was visited every two months, and the other group after a six-month interval. There was also a control group. At the six-month follow-up, the two intervention groups did not differ with respect to $\mathrm{Ul}$, therefore the original two intervention groups were combined, leaving a single intervention group and a control group. The authors conducted a completer's only analysis and reported that incontinence decreased in the experimental group (28 of the 44 participants still in the study at six months) with almost no change in the control group. Further analysis of this data using the non-parametric sign test was conducted, demonstrating a significant decrease in the experimental group $(Z=-1.83, p<.05)$. The participants were coded according to any decrease in percentage of incontinent episodes versus staying the same or not showing improvement in incontinence. However, two previous reviews conducted a re-analysis of the data which found that although the results favoured the experimental groups, they were not statistically significant $[41,88]$.

\section{Objective three and overarching synthesis}

The third objective was to identify the facilitators and barriers around developing communication strategies and individualised management plans in response to the continence needs of PLWD. In addressing this objective, a matrix that consisted of three overarching final synthesised findings (communication that is dignified, person centred and respectful,

Page 25/39 
communication during outpatients appointments and delivering individualised continence care) was juxtaposed with barriers and facilitators alongside the results of interventions was produced (see Table 5). The extent to which the review findings are reasonable representations of each theme using the GRADE and CERQual approach is presented alongside each component of the overarching syntheses. Where there were no research studies that presented information on barriers or facilitators, we drew on the information within the non-research material. 
Table 5

Overarching synthesis matrix that juxtaposed barriers and facilitators alongside the results of interventions

View on barriers and facilitators

Interventions that address

barriers or build on facilitators

Synthesised finding 1: Communication that is dignified, person centred and respectful

Barriers Facilitators Interventions

Communicating in a dignified way

PLWD \& their carers find talking about incontinence distressing and embarrassing

CERQual:Moderate / Studies $2,3,4$
HCPs to build trust and rapport through using humour, having appropriate knowledge and skills by speaking quietly and keeping incontinence issues secret
None identified

CERQual:Moderate / Studies 2, 3,4

The attitudes of HCPs towards continence and continence care

HCPs often ignore toileting requests or avoid routine toileting citing being busy or being uncomfortable with or disinterested in toileting

CERQual:Very Low / Study 2, 12

Staff in acute settings do not consistently promote continence
HCPs having respect building relationships and using appropriate language

CERQual: Very Low / Study 2

Interpersonal and communication skills are important and should be a focus of education programs [83, 84]

(Non research:Ungraded)
None identified

CERQual:Very Low / Study 14

The importance of non- verbal cues

PLWD are not always able to recognise and communicate that they need to go to the toilet or indicate that they need assistance [37, 78-80] and they use a variety of nonverbal cues to indicate that they need to go to the toilet $[37,76,77,79,85]$

CERQual High: Study 1, 2, 3, 4, $5,6,7,10,11,12$

(Non research:Ungraded)
Finding out what words or phrases that PLWD use for describing the toilet $[38,67,77,79,80]$ as well as being able to recognise familiar gestures or is seen as important $[38,67,80]$

Non research:Ungraded

HCPs checking PLWD awareness of communication techniques including non-verbal cues through communicating with the family

CERQual: Low / Studies 2, 13

HCPs being able to recognize the non-verbal signals, body language, facial expressions, behaviours and signs that PLWD use to communicate that they need to go toilet and this should be a focus education programs for new staff

CERQual: Low / Studies 2, 12
None identified 
People living with moderate dementia preferred the word toilet compared to those with normal cognition and those with advanced dementia preferred the international symbol for toilet compared to those with mild or normal cognition

CERQual:Very Low / Study 7

General communication strategies

HCPs introducing themselves and seeking PLWD approval before performing tasks

CERQual:Very Low / Study 4

A range of strategies have been identified that include getting to know the PLWD \& how they communicate and manage their continence, communicating with the family, prompting, seeing the person has an individual, and checking HCPs communication skills $[37,38,77-80,86]$

(Non research:Ungraded)

Using technology to present instructions

Verbal instructions, presented automatically through simple technology has the potential to be effective in helping persons with mild or moderate levels of $A D$ go to the toilet independently by presenting simple step wise sequential instructions Grade:Very Low /

Studies 5, 6

\section{Synthesised finding 2: Communication during outpatient appointments}

Barriers Facilitators Interventions

Presence of PLWD during outpatient consultations

Caregivers felt having the PLWD with them during outpatient consultations could cause unnecessary anxiety

CERQual:Very Low / Study 1
Caregivers felt having the PLWD with them during outpatient consultations would allow greater cooperation with management strategies

CERQual:Very Low / Study 1

HCPs felt it was important that

PLWD were present at

appointments
None identified

None identified

CERQual:Very Low / Study 3

Initiating conversations during outpatient consultations

Key: HCP: health care professional; PLWD: People living with dementia 


\section{View on barriers and facilitators}

ncertainty over who should initiate conversations during consultations

HCPs suggested developing a previsit checklist to prompt conversation during consultations
Interventions that address

barriers or build on facilitators

CERQual: Very Low / Study $3 \quad$ CERQual:Very Low / Study 3

The language of incontinence during outpatient consultations

Incontinence and management options after often explained in terms that caregiver find difficult to understand.
HCPs suggested handouts that could offer more detailed explanations to take home

CERQual:Very Low / Study 3
None identified

None identified

CERQual: Low / Study 1, 3

Communication strategies for outpatient appointments

Caregivers and HCPs suggested developing a caregiver guide that would be available prior to the consultation or handouts that caregivers could take away with them afterwards
None identified

CERQual:Low / Study 1, 3

\section{Synthesised finding 3: Delivering individualised continence care}

\section{Barriers}

Facilitators

Importance of individualised continence care

$$
\begin{aligned}
& \text { Targeted and } \\
& \text { individualised/person centred } \\
& \text { continence care that is established } \\
& \text { after a thorough assessment has } \\
& \text { taken place is seen as important } \\
& {[31,37,73,75,79,81,83,85]} \\
& \text { (Non research:Ungraded) } \\
& \text { Individualized continence care is } \\
& \text { about what is best for the PLWD } \\
& \text { and avoiding harm and about } \\
& \text { promoting autonomy and } \\
& \text { independent living [37, 79] }
\end{aligned}
$$

(Non research:Ungraded)
Interventions

None identified

Components of individualised care plans 


\section{View on barriers and facilitators}

Individualised care plans should consider the needs of both PLWD and their caregivers and involve multi-components exploring both day-time and night care of incontinence are helpful in addressing incontinence in the home care setting $[31,37,75,81-$ 83]

(Non research:Ungraded)

\section{Interventions that address}

\section{barriers or build on facilitators}

An intervention that involved individualized and comprehensive care for residents in a care home that focused on providing adequate fluids and meal by encouraging patients to use toilets was effective for $19 \%$ of residents in reducing the proportion of diapers used

\section{Grade:Very Low / Study 9}

An intervention that involved individual treatment strategies delivered by an occupational therapist and designed to enhance the caregiver's ability to problem solve about their environment. A post intervention survey reported that this approach enabled caregivers to develop effective solutions to situations they considered problematic which included toileting

\section{CERQual:Very Low / Studies 10, 11}

An intervention that involved training health workers in person centred care was effective in improving the quality of care and a reduction in the number of aids needed to manage incontinence

GRADE:Very Low / Study 14

Health care professionals and caregivers working in partnership

It is important that HCPs and caregivers work together to deliver individualized/person centred continence care $[75,79,81,82]$
None identified

(although a feature of three intervention studies $(62,65,66)$

(Non research:Ungraded)

Establishing a toileting routine within the home environment

The importance of developing a regular toileting schedule was highlighted by caregivers [37]

CerQUAL: Very Low / Study 10

(Non research:Ungraded)
An individualized scheduled toileting program that compensated for cognitive impairment by providing memory-impaired patients with toileting reminders was not been shown to any significant benefits in terms of improving the number of incontinent episodes for PLWD in a home care setting

Grade:Very Low / Study 8

Key: HCP: health care professional; PLWD: People living with dementia

\section{Discussion}

Maintaining continence has been highlighted as a major issue for patients with long term conditions, which includes PLWD, and understanding the best ways to support continence and the management of incontinence in PLWD has been recognised as a research priority [89]. This review is therefore timely and offers up a summary of the available knowledge to date that stakeholders and those caring for PLWD identified as important; key issues were communication and 
individualised care planning. The aim of the final synthesis was to identify the facilitators and barriers associated with developing communication strategies and individualised management plans to support the continence needs of PLWD.

The first overarching synthesis highlighted with a high level of confidence that PLWD are not always able to recognise that they have continence needs, need to go to the toilet, or verbally communicate that they need assistance. The wider literature acknowledges that patients with long term conditions including PLWD can maintain continence with assistance, but that the reality is often that many are unnecessarily treated as incontinent in hospital and care home settings [89]. This synthesis demonstrates identified that continence care is considered a low priority by some frontline staff and that they are sometimes unable e to recognise when PLWD have continence needs unless it is verbally communicated. It also highlighted that a variety of non-verbal cues are often used by PLWD to indicate their continence needs and that this can be further facilitated when HCPs familiarise themselves with the words or phrases and non-verbal signals such as facial expressions, familiar gestures, behaviours, or signs, that each PLWD uses to communicate this need. There was low quality evidence to suggest that some staff do not appear to consistently promote continence and in some instances were too busy or disinterested to support individual continence care in a acute settings. Although a range of communication strategies have been suggested in the non-research literature, what is needed is a renewed focus on improving both verbal and non-verbal communication strategies and recognition, so that distress around the use of language and embarrassment around maintaining continence for PLWD can be minimised. To facilitate continence care across all settings it is important that training of those who work with PLWD and their carers should include continence care that also incorporates the skills of interpersonal communication and recognition. A recent collaborative workshop addressing the need for continence research also highlighted that there is currently a lack of training for health and social care professionals in continence issues [89].

Although some evidence maps across, there are important gaps between what caregivers and HCPs have identified as deficiencies in continence care for PLWD when considering communication, and a lack of robustly evaluated interventions which attempt to address these deficiencies. This evidence gap is reflective of the wider evidence base of dementia care and communication more widely. For example, Machiels et al., reported that only a few intervention studies concerned with how communication between nursing staff and PLWD can be improved [90] and Eggenberg et al., found no studies which looked at identifying ways to improve communication between physicians and PLWD [91] More research is needed to support effective care. A previous review found that when training in communication skills has been conducted with professional and family caregivers, then the quality of life and wellbeing of PLWD in both nursing homes and home-care settings was improved, which in turn increased positive interactions [91].

The second overarching synthesis finding comprised low quality evidence that explored different aspects of communication occurring between PLWD, caregivers, and HCPs during outpatient appointments. The caregivers' role has been characterised as is one of both an informant and an advocate during an outpatient appointment [92]. The synthesis showed that HCPs feel it is important that PLWD were present at outpatient appointments, however, caregivers expressed divided opinions as to whether PLWD should attend outpatient appointments with them. Previous research on doctorpatient communication has focused on disclosing a diagnosis of dementia [4] and caregivers report discomfort in the presence of the PLWD when divulging sensitive information [93]. An educational intervention that sought to improve patient centred care for PLWD and their carers during medical encounters with old age psychiatrists suggested a number of changes to the consultation structure [94]. One of which was to offer the PLWD and carer a choice of whether they attended the consultation separately as well as together in order than patient centred care during their consultations could be developed. We did not find any evidence of any strategies for use in outpatient settings to better support PLWD, their families, or staff, about incontinence and promote continence. The ongoing care of PLWD in both an outpatient and primary care setting when managing continence issues is an area that requires further research.

The final overarching synthesis was concerned with the delivery of individualised continence care. It is well documented in a number of guidelines and across the material produced by the various charities, that individualised care plans should

Page $31 / 39$ 
consider the needs of both PLWD and their caregivers, and involve multi-components exploring both day-time and night care of incontinence if they are to be helpful in facilitating continence. What this synthesis revealed is that there is a lack of interventions related to the delivery of individualised continence care for PLWD and only three intervention studies [62, $65,66]$ providing low quality evidence were identified that incorporated some aspect of individualised care. Hagglund in her systematic review of incontinence care for PLWD also reported a lack of evidence-based interventions and pointed out the need for the "effective continence-promoting interventions and improved individualized nursing" (Hagglund 2000, p. 311). There is evidence also of a "policy/practice-research gap", given there is a significant and well-meaning focus on person-centred care in policy and practice yet there is little research to support staff in how to achieve this in practice. It is also recognised as important that HCPs and caregivers work together to deliver individualized/person centred continence care for PLWD. Each PLWD is unique and HCPs need to be enabled to recognise the specific individual needs of each person as opposed to assuming a "one size fits all" approach when it comes to continence care. Continence care needs to be personalised and responsive to the PLWD preferences and needs.

\section{Limitations}

The search was for English-language only materials. The studies included in this review varied in methodological quality, which impacts on the overall results and conclusions that can be drawn. A strength of this review has been the inclusion of the views and interests of stakeholders, including PLWD which led us to focus on communication and individualised care. Another strength of this review was the use of the CERQual approach which allowed us to determine a level of confidence in the synthesized review findings.

\section{Conclusions}

The findings from the syntheses derived from this review of the international literature can help with informing innovations in continence care for PLWD in the acute hospital setting. Recognising that PLWD are not always able to verbally communicate their continence needs or that they require assistance is important. Incorporating interpersonal and communication skills in the context of continence care for those working with PLWD is crucial for continence to be supported and maintained in the acute setting. Training of those who work with PLWD and their carers should include continence care and also incorporate interpersonal and communication skills.

Developing and implementing interventions that seek to improve the delivery of individualised continence care within the acute setting that can be tried and tested, and could be "rolled out" to suit the majority of PLWD and their caregivers would be difficult. Taking into the account the varying and many needs of individual people, their circumstances, and symptoms, would make such interventions challenging. The complexity of living with continence problems alongside any other longterm health conditions such as dementia has been acknowledged, however, addressing this requires a holistic approach (Age UK 2018). What we do know is that continence care in the acute setting, which is tailored to the individual and that is developed in partnership with HCPs and caregivers is more likely to be successful.

\section{Abbreviations}

\section{AD: Alzheimer's Disease:}

CERQual: Confidence in the Evidence from Reviews of Qualitative research

Fl: faecal incontinence

GRADE: Grading of Recommendations Assessment, Development, and Evaluation

HCP: health care professionals

Page $32 / 39$ 
LTCF: long term care facility

PLWD: people living with dementia

RCT: randomised controlled trials

Ul: urinary incontinence

\section{Declarations}

\section{Ethics approval and consent to participate}

Not applicable

\section{Consent for publication}

Not applicable

\section{Competing interests}

The authors declare that they have no competing interests

\section{Funding}

This study/project is funded by the National Institute for Health Research (NIHR) Services and Delivery Research Programme (project reference15/136/67/). The views expressed are those of the author(s) and not necessarily those of the NIHR or the Department of Health and Social Care.

\section{Authors' contributions}

$\mathrm{KF}, \mathrm{JH}, \mathrm{DE}, \mathrm{AJ}$ conceived the study.

DE, JH designed the study.

DE, JH selected the articles, appraised articles, extracted data.

DE synthesised the data and wrote the first draft of the manuscript.

$\mathrm{KF}, \mathrm{JH}, \mathrm{DE}, \mathrm{AJ}$ interpreted the data and contributed to the writing of the final version of the manuscript. The author(s) read and approved the final manuscript.

DE is the guarantor and affirms that the manuscript is an honest accurate and transparent account of the study being reported that no important aspects of the study have been omitted, and that any discrepancies from the study as planned have been explained

Authors information

Not applicable

Acknowledgements

References 
1. Wittenberg R, Hu B, Barraza-Araiza L, Rehill A. Projections of older people with dementia and costs of dementia caare in the United Kingdom 2019-2040 [Internet]. London Schoolof Economics and Political Science: Care Policy and Evaluation Centre; 2019. Available from: https://www.alzheimers.org.uk/sites/default/files/201911/cpec_report_november_2019.pdf

2. World Health Organisation. Dementia [Internet]. 2019 [cited 2020 Aug 11]. Available from: https://www.who.int/newsroom/fact-sheets/detail/dementia

3. Alzheimer's Society. Dementia UK Update. London: Alzheimer's Society; 2014.

4. Prince M, Wimo A, Guerchet M, Ali G-C, Wu Y-T, Prina W. World Alzheimer Report 2015. The Global Impact of Dementia. An analysios of prevalence, incidence, cost and trends. London: Alzheimer's Disease International; 2015.

5. Abrams P, Cardozo L, Khoury S, Wein A. Incontinence. 5th International Consultation on Incontinence Paris February 2012. 5th ed. ICUD-EAU; 2013.

6. Abrams P, Cardozo L, Fall M, Griffiths D, Rosier P, Ulmsten U, et al. The standardisation of terminology of lower urinary tract function: Report from the standardisation sub-committee of the International Continence Society. Neurourol Urodyn. 2002;21:167-78.

7. Norton C, Whitehead WE, Bliss DZ, Harari D, Lang J. Management of fecal incontinence in adults. Neurourol Urodyn. 2010;29:199-206.

8. Goodman C, Norton C, Buswell M, Russell B, Harari D, Harwood R, et al. Managing Faecal INcontinence in people with advanced dementia resident in Care Homes (FINCH) study: a realist synthesis of the evidence. Health Technol Assess. 2017;21:1-220.

9. Yap P, Tan D. Urinary incontinence in dementia. A practical approach. Aust Fam Physician. 2006;35:237-41.

10. Alzheimer's Europe. Guidelines on continence care for people with dementia living at home. Luzembourg: Alzheimer's Europe; 2014.

11. Bickel H, Hendlmeier I, Heßler JB, Junge NJ, Leonhardt-Achilles S, Weber J, et al. The prevalence of dementia and cognitive impairment in hospitals. Results from the General Hospital Study (GHoSt). Dtsch Arzteblatt Int. 2018;115:733-40.

12. Briggs R, Dyer A, Collins R, Doherty J, Coughlan T, O'Neill D, et al. Dementia in the acute hospital: the prevalence and clinical outcomes of acutely unwell patients with dementia. QJM. 2017;110:33-7.

13. Timmons S, Manning E, Barrett A, Brady NM, Browne V, O'Shea E, et al. Dementia in older people admitted to hospital: a regional multi-hospital observational study of prevalence, associations and case recognition. Age Ageing. 2015;44:993-9.

14. Sampson EL, Blanchard MR, Jones L, Tookman A, King M. Dementia in the acute hospital: prospective cohort study of prevalence and mortality. Br J Psychiatry. 2009;195:61-6.

15. Travers C, Bryne G, Pachana N, Klein K, Gray L. Prospective observational study of dementia and delirium in the acute hospital setting. Intern Med J. 2013;43:262-9.

16. Lakey L. Counting the Costs. Caring for people with dementia on hospital wards. London: Alzheimer's Society; 2009.

17. Alzheimer's Society. Fix Dementia Care: Hospitals. London: Alzheimer's Society; 2016.

18. Ouslander JG, Zarit SH, Orr NK, Muira SA. Incontinence among elderly community-dwelling dementia patients. Characteristics, management, and impact on caregivers. J Am Geriatr Soc. 1990;38:440-5.

19. Potter J, Peel P, Mian S, Lowe D, Irwin P, Pearson M, et al. National audit of continence care for older people: management of faecal incontinence. Age Ageing. 2007;36:268-73.

20. Wagg A, Harari D, Husk J, Lowe D, Lourtie J. National Audit of Continence Care. London: Royal College of Physicians; 2010.

21. Harari D, Husk J, Lowe D, Lourtie J. Pilot audit evaluation report. London: Royal College of Physicians; 2012. 
22. Calnan M, Tadd W, Calnan S, Hillman A, Read S, Bayer A. 'I often worry about the older person being in that system': exploring the key influences on the provision of dignified care for older people in acute hospitals. Ageing Soc. 33:46585.

23. Ostaszkiewicz J, O’Connell B, Dunning T. Residents' perspectives on urinary incontinence: a review of literature. Scand J Caring Sci. 2012;26:761-72.

24. Furlanetto K, Emond K. "Will I come home incontinent?" A retrospective file review: Incidence of development of incontinence and correlation with length of stay in acute settings for people with dementia or cognitive impairment aged 65 years and over. Collegian. 2016;23:79-86.

25. Colborne M, Dahlke S. Nurses' perceptions and management of urinary incontinence in hospitalized older adults: An integrative review. Jourmal Gerontol Nurs. 2017;43:46-55.

26. Oliver D, Healey F, Haines TP. Preventing falls and fall-related injuries in hospitals. Clin Geriatr Med. 2010;26:645-92.

27. Lim SC, Mamun K, Lim JKH. Comparison between elderly inpatient fallers with and without dementia. Singapore Med J. 2014;55:67-71.

28. Kranz J, Schmidt S, Wagenlelner F, Schneidewind L. Catheter-associated urinary tract infections in adult patients. Preventive strategies and treatment options. Dtsch Arzteblatt Int. 2020;117:83-8.

29. Loveday HP, Wilson JA, Pratt RJ. Loveday HP, Wilson JA, and Pratt RJ (2014) Epic3: national evidence-based guidelines for preventing healthcare associated infections in NHS hospitals in England. Journal Hospital Infection 86 (1 Suppl): S1-70. J Hosp Infect. 86:S1-70.

30. Li H-C, Chen K-M, Hsu H-F. Modelling factors of urinary incontinence in institutional older adults with dementia. J Clin Nurs. 2019;28:4504-12.

31. Hollenbeak CS, Schilling AL. The attributable cost of catheter-associated urinary tract infections in the United Stated: A systematic review. Am J Infect Control. 2018;46:751-7.

32. Bagnola E, Pearce E, Broome B. A review and case study of urinary incontinence. Madridge J Nurs. 2017;2:27-31.

33. Abrams P, Cardozo L, Wagg A, Wein A. 6th International Consultation on Incontinence. Bristol, UK: ICI-ICS. International Continence Society; 2017.

34. Cole L, Drennan V. Living with incontinence: the experience of people with dementia. Dementia. 2019;18:1826-39.

35. Bamford S-M, Holley-Moore G, Watson J. A compendium of essays: New perspectives and appraoches to understanding dementia and stigma. London: ILC_UK; 2014.

36. Benbow SM, Jolley D. Dementia: stigma and its effects. Neurodegener Dis Manag. 2.

37. Drennan VM, Cole L, lliffe S. A taboo within a stigma? a qualitative study of managing incontinence with people with dementia living at home. BMC Geriatr. 2011;11:75.

38. Gove D, Scerri A, Georges J, Houten P, Huige N, Hayder-Beichel D, et al. Continence care for people with dementia living at home in Europe: a review of literature with a focus on problems and challenges. J Clin Nurs. 2017;26:356-65.

39. DuBeau CE, Kuchel GA, Johnson T, Palmer MH, Wagg A. Incontinence in the frail elderly. 4th International Consultation on Incontinence. Recommendations of the International Scientific Committee: Evaluation and Treatment of Urinary Incontinence, Pelvic Organ Prolapse and Faecal Incontinence. 4th ed. Paris, France: Health Publication Ltd, 961-1024. 2009.

40. Hagglund D. A systematic literature review of incontinence care for persons with dementia: the research evidence. J Clin Nurs. 2010;19:303-12.

41. Drennan VM, Greenwood N, Cole L, Fader M, Grant R, Rait G, et al. Conservative interventions for incontinence in people with dementia or cognitive impairment, living at home: a systematic review. BMC Geriatr. 2012;12:77.

42. Featherstone K, Northcott A, Harden J, Boddington P, Vougiokalou S, Edwards D, et al. Understanding how to facilitate continence for people with dementia in acute hospital settings: Raising awarness and improving care [Internet]. Natl. 
Inst. Health Res. J. Libr. 2017. Available from: https://www.journalslibrary.nihr.ac.uk/programmes/hsdr/1513667/\#/

43. EPPI-Centre. EPPI-Centre methods for conducting systematic reviews. London: Institute of Education, University of London; 2007 Updated 2010.

44. Gough D, Oliver S, Thomas J. An Introduction to Systematic Reviews'. London: Sage; 2017.

45. Moher D, Liberati A, Tetzlaff J, Altman DG. Preferred reporting items for systematic reviews and meta-analyses: the PRISMA statement. Ann Intern Med. 2009;151:264-9.

46. Tricco A, Lillie E, Zarin W, O'Brien K, Colquhoun H, Levac D, et al. PRISMA extension for scoping reviews (PRISMA-ScR): Checklist and explanation. Ann Intern Med. 2018;169:467-73.

47. Hay-Smith J, Berghmans B, Burgio K, Dumoulin C, Hagen S, Moore K, et al. Adult Conservative Measures in Incontinence. In: Abrams P, Cardozo L, Khoury S, Wein A, editors. 4th Int Consult Incontinence. Paris: Health Publications; 2008.

48. Arksey H, O'Malley L. Scoping studies: towards a methodological framework. Int J Soc Res Methodol. 2005;8:19-32.

49. Delbecq A, Van de Ven A. Group techniques for program planning a guide to nominal group and delphi processes. California: Sage; 1975.

50. Harvey N, Holmes CA. Nominal group technique: an effective method for obtaining group consensus. Int J Nurs Pract. 2012;18:188-94.

51. Grant AM, Cody DJ, Glazener CMA, Hay-Smith J, Herbison P, Lapitan MC, et al. Cochrane Incontinence Group. About The Cochrane Collaboration (Cochrane Review Groups (CRGs)) 2012, Issue 12. Art. No.: INCONT. Cochrane Collab. 2012;18 January:Art. No.: INCONT.

52. Centre for R, Dissemination. CRD's guidance on undertaking reviews in health care. York: University of York CRD; 2009.

53. Pace R, Pluye P, Bartlett G, Macaulay AC, Salsberg J, Jagosh J, et al. Testing the reliability and efficiency of the pilot mixed methods appraisal tool (MMAT) for systematic mixed studies review. Int J Nurs Stud. 2012;49:47-53.

54. Pluye P, Gagnon M-R, Griffiths F, Johnson-Lafleur J. A scoring system for appraising mixed methods research, and concomitantly appraising qualitative, quantitative and mixed methods primary studies in Mixed Studies Reviews. Int J Nurs Stud. 2009;46:529-46.

55. Thomas J, Harden A. Methods for the thematic synthesis of qualitative research in systematic reviews. BMC Med Res Methodol. 2008;8.

56. Guyatt GH, Oxman AD, Vist GE, Kunz R, Fiack-Ytter Y, Alosno-Coello P, et al. GRADE: an emerging consensus on rating quality of evidence and strength of recommendations. BMJ. 2008;336:924-6.

57. Lewin S, Glenton C, Munthe-Kaas H, Carlsen B, Colvin C, Gülmezoglu M, et al. Using qualitative evidence in decision making for health and social interventions: an approach to assess confidence in findings from qualitative evidence syntheses (GRADE-CERQual). PLOS Med. 2015;12:e1001895.

58. Edwards D, Noyes J, Lowes L, Haf Spencer L, Gregory JW. An ongoing struggle: a mixed-method systematic review of interventions, barriers and facilitators to achieving optimal self-care by children and young people with type 1 diabetes in educational settings. BMC Pediatr. 2014;14.

59. Hannigan B, Edwards D, Evans N, Gillen E, Longo M, Pryjmachuk S, et al. An evidence synthesis of risk identification, assessment and management for young people using tier 4 inpatient child and adolescent mental health services. Health Serv Deliv Res. 2015;3.

60. Lancioni GE, La Martire ML, Singh NN, O’Reilly MF, Sigafoos J, Pinto K, et al. Persons with mild or moderate Alzheimer's disease managing daily activities via verbal instruction technology. Am J Alzheimers Dis Other Demen. 2009;23:552-62.

61. Lancioni GE, Pinto K, La Martire ML, Tota A, Rigante V, Tatulli E, et al. Helping persons with mild or moderate Alzheimer's disease recapture basic daily activities through the use of an instruction strategy. Disabil Rehabil.

Page 36/39 
2009;31:211-9.

62. Jirovec MM, Templin T. Predicting success using individualized scheduled toileting for memory-impaired elders at home. Res Nurs Health. 2001;24:1-8.

63. Tanaka Y, Hanata K, Tanaka T, Kuwano K, Endo H, Otano T, et al. Can an individualized and comprehensive care strategy improve urinary incontinence (UI) among nursing home residents? Arch Gerontol Geriatr. 2009;49:278-83.

64. Wijk H, Corazzini K, Lindstrom K, Kinnander A, Alexiou E, Swedberg K. Person-centrered incontinence care in residential care facilities for older adults with cognitive decline. J Gerontol Nurs. 2018;44:11-9.

65. Corcoran MA, Gitlin LN. Family caregiver acceptance and use of environmental strategies provided in an occupational therapy intervention. Phys Occup Ther Geriatr. 2001;19:1-20.

66. Gitlin LN, Corcoran MA. Expanding caregiver ability to use environmental solutions for problems of bathing and incontinence in the elderly with dementia. Technol Disabil. 1993;2:12-1.

67. Wilkinson TJ, Henschke PJ, Handscombe K. How should toilets be labelled for people with dementia? Australas J Ageing. 1995;14:163-5.

68. Shih YH, Wang CJ, Sue EP, Wang JJ. Behavioral characteristics of bowel movement and urination needs in patients with dementia in Taiwan. J Gerontol Nurs. 2015;41:22-9.

69. Iliffe S, Wilcock J, Drennan V, Goodman C, Griffın M, Knapp M. Changing practice in dementia care in the community: developing and testing evidence-based interventions, from timely diagnosis to end of life (EVIDEM). Southampton (UK): NIHR Journals Library; 2015.

70. Bliss D, Rolnick C, Jackson J, Arntson C, Mullins J, Hepburn K. Health literacy needs related to incontinence and skin damage among family and friend caregivers of individuals with dementia. J Wound Ostomy Continence Nurs. 2013;40:515-23.

71. Mullins J, Bliss DZ, Rolnick S, Henre CA, Jackson J. Barriers to communication with a healthcare provider and health literacy about incontinence among informal caregivers of individuals with dementia. J Wound Ostomy Continence Nurs. 2016;43:539-44.

72. Rolnick S, Bliss DZ, Jackson JM, Arntson C, Mullins J, Hepburn K. Healthcare providers' perspectives on communicating incontinence and skin damage information with patients with dementia and their family caregivers: a descriptive study. Ostomy Wound Manag. 2013;59:62-7.

73. Ostaszkiewicz J, Tomlinson E, Hutchinson AM. "Dignity”: A central construct in nursing home staff understandings of quality continence care. J Clin Nurs. 2018;27:2425-37.

74. Scerri A, Scerri C, Innes A. The perceived and observed needs of patients with dementia admitted to acute medical wards. Dementia. 2018;Onlilne first:1-21.

75. Alzheimer's Society. Managing toilet problems and incontinence', Factsheet 502LP [Internet]. 2016 [cited 2018 Jul 7]. Available from:

https://www.alzheimers.org.uk/sites/default/files/migrate/downloads/factsheet_continence_and_using_the_toilet.pdf

76. Alzheimer's Society, Gray C. Support and care for people with dementia at home: A guide for homecare workers [Internet]. London: Alzheimer's Society; 2014. Available from: https://www.alzheimers.org.uk/get-support/publicationsand-factsheets/home-guide-homecare-workers

77. Dementia UK. Continence [Internet]. 2017 [cited 2018 Jul 7]. Available from: http://www.dementiauk.org/wpcontent/uploads/2018/06/Continence_FINAL_WEB_JUNE-2018.pdf

78. Social Care Institute for Excellence. When people with dementia experience problems related to using the toilet. 2015.

79. Care Inspectorate. Promoting continence for people living with dementia and long term conditions [Internet]. 2015 [cited $2018 \mathrm{Jul}$ 7]. Available from: http://www.careinspectorate.com/index.php/guidance/9-professional/2613promoting-continence-for-people-living-with-dementia-and-long-term-conditions

Page $37 / 39$ 
80. National Collaborating Centre for Mental Health. A NICE-SCIE guideline on supporting people with dementia and their carers in health and social care. Clinical guideline [CG42]. Leicester, UK: The British Psychological Society \& The Royal College of Psychiatrists; 2007.

81. Care Quality Commission. Cracks in the pathway. People's experiences of dementia care as they move between care homes and hospitals [Internet]. Gallowgate, UK: Care Quality Commission; 2014. Available from: https://www.cqc.org.uk/sites/default/files/20141009_cracks_in_the_pathway_final_0.pdf

82. Thompson R, Health H, Mills N. Dementia: Commitment to the care of people with dementia in hospital settings. London: Royal College of Nursing; 2013.

83. Potter P. Excellence in continence care; Practical guidance for commissioners, providers, health and social care staff and information for the public. Reading, UK: NHS England; 2015.

84. Ostaszkiewicz J. Reframing continence care in care-dependence. Geriatr Nur (Lond). 2017;38:520-6.

85. Ostaszkiewicz J. A conceptual model of the risk of elder abuse posed by incontinence and care dependence. Int $\mathrm{J}$ Older People Nurs. 2018;13:e12182.

86. Alzheimer's Scotland. Continence management - advice for carers of people with dementia [Internet]. Edinburgh: Alzheimer Scotland; 2009. Available from: https://www.alzscot.org/assets/0000/0159/continence.pdf

87. Hutchinson S, Leger-Krall S, Skodol Wilson H. Toileting: a biobehavioral challenge in Alzheimer's dementia care. J Gerontol Nurs. 1996;22:18-27.

88. Ostaszkiewicz J, Johnston L, Roe B. Timed voiding for the management of urinary incontinence in adults. Cochrane Database Syst Rev. 2004;CD002802.

89. Age UK. "My bladder and bowel own my life". A collaborative workshop addressing the need for continence research [Internet]. London: Age UK; 2018. Available from: https://www.alzheimers.org.uk/sites/default/files/2018-

08/Incontinence\%20needs\%20-\%202018\%20report\%20v9.pdf

90. Machiels M, Metzelthin SF, Hamers JPH, Zwakhalen SMG. Interventions to improve communication between people with dementia and nursing staff during daily nursing care: A systematic review. Int J Nurs Stud. 2017;66:37-46.

91. Eggenberger E, Heimerl K, Bennett Ml, Eggenberger E, Heimerl K, Bennett Ml. Communication skills training in dementia care: a systematic review of effectiveness, training content, and didactic methods in different care settings. Int Psychogeriatr. 2013;25:345-58.

92. Dooley J, Bailey C, McCabe R. Communication in healthcare interactions in dementia: a systematic review of observational studies. Int Psychogeriatr. 2015;27:1277-300.

93. Hunsaker AE, Schmidt K, Lingler JH. Discussing dementia-related behaviors during medical visits for people with Alzheimer's disease. Am J Alzheimer's Dis Dement. 25:248-54.

94. Robinson L, Bamford C, Briel R, Spencer J, Whitty P. Improving patient-centered care for people with dementia in medical encounters: an educational intervention for old age psychiatrists. Int Psychogeriatr. 2010;22:129-38.

\section{Figures}




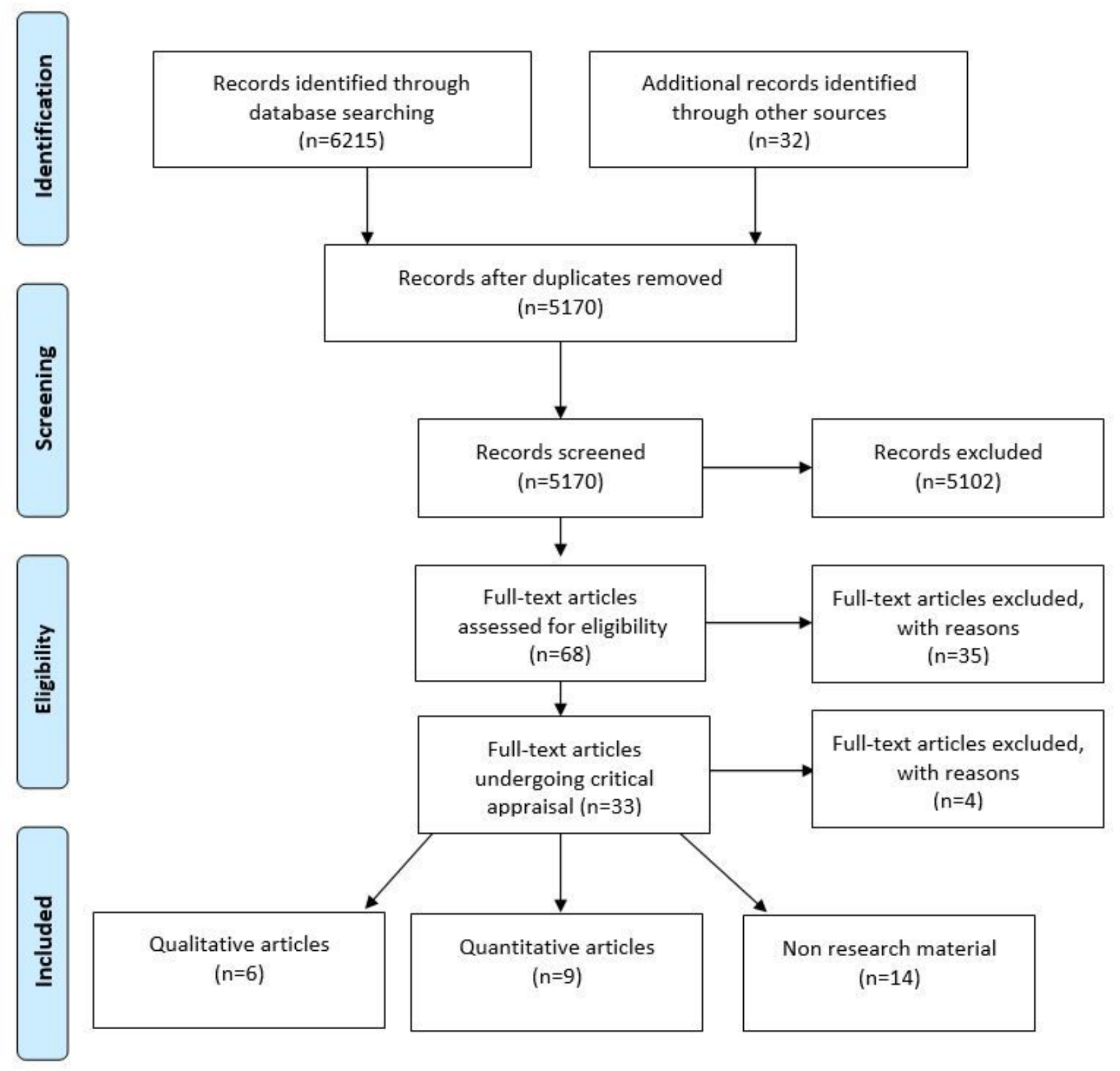

Figure 1

Flow of studies through review

\section{Supplementary Files}

This is a list of supplementary files associated with this preprint. Click to download.

- Additionalfiles1.docx

- AdditionalfileS2.docx

- AdditionalfileS3.docx

- AdditionalfileS4.docx 